\title{
p75 Neurotrophin Receptor Activation Regulates the Timing of the Maturation of Cortical Parvalbumin Interneuron Connectivity and Promotes Juvenile-like Plasticity in Adult Visual Cortex
}

\author{
Elie Baho, ${ }^{1,2 *}$ Bidisha Chattopadhyaya, ${ }^{1,2 *}$ Marisol Lavertu-Jolin, ${ }^{1,2 *}$ Raffaele Mazziotti, ${ }^{3}$ (Datricia N. Awad, ${ }^{1,2}$ \\ (DPegah Chehrazi, ${ }^{1,2}$ Marianne Groleau, ${ }^{4}$ Celine Jahannault-Talignani, ${ }^{5}$ Elvire Vaucher, ${ }^{4}$-Fabrice Ango, ${ }^{5}$ \\ -Tommaso Pizzorusso, ${ }^{3,6}$ - Laura Baroncelli, ${ }^{3}$ and ${ }^{-G}$ Graziella Di Cristo ${ }^{1,2}$ \\ ${ }^{1}$ Department of Neurosciences, Université de Montréal, Montréal, Québec H3T 1J4, Canada, ${ }^{2}$ Centre de Recherche, Centre Hospitalier Universitaire \\ Sainte-Justine, Montréal, Québec H3T 1C5, Canada, ${ }^{3}$ Institute of Neuroscience Consiglio Nazionale delle Ricerche, 56124 Pisa, Italy, 4École d’Optométrie, \\ Université de Montréal, Montréal, Québec H3T 1P1, Canada, ${ }^{5}$ Institut de Génomique Fonctionnelle, université de Montpellier, Centre National de la \\ Recherche Scientifique, Institut National de la Santé Et de la Recherche Médicale, 34090 Montpellier, France, and ${ }^{6}$ Department of Neuroscience, \\ Psychology, Drug Research and Child Health Neurofarba, University of Florence, 50139 Firenze, Italy
}

By virtue of their extensive axonal arborization and perisomatic synaptic targeting, cortical inhibitory parvalbumin (PV) cells strongly regulate principal cell output and plasticity and modulate experience-dependent refinement of cortical circuits during development. An interesting aspect of $\mathrm{PV}$ cell connectivity is its prolonged maturation time course, which is completed only by end of adolescence. The p75 neurotrophin receptor (p75NTR) regulates numerous cellular functions; however, its role on cortical circuit development and plasticity remains elusive, mainly because localizing p75NTR expression with cellular and temporal resolution has been challenging. By using RNAscope and a modified version of the proximity ligation assay, we found that p75NTR expression in PV cells decreases between the second and fourth postnatal week, at a time when PV cell synapse numbers increase dramatically. Conditional knockout of p75NTR in single PV neurons in vitro and in PV cell networks in vivo causes precocious formation of PV cell perisomatic innervation and perineural nets around PV cell somata, therefore suggesting that p75NTR expression modulates the timing of maturation of PV cell connectivity in the adolescent cortex. Remarkably, we found that PV cells still express p75NTR in adult mouse cortex of both sexes and that its activation is sufficient to destabilize PV cell connectivity and to restore cortical plasticity following monocular deprivation in vivo. Together, our results show that p75NTR activation dynamically regulates PV cell connectivity, and represent a novel tool to foster brain plasticity in adults.

Key words: critical period plasticity; GABAergic perisomatic synapses; ocular dominance plasticity; p75NTR; perineural nets; PV cells

Significance Statement

In the cortex, inhibitory, GABA-releasing neurons control the output and plasticity of excitatory neurons. Within this diverse group, parvalbumin-expressing (PV) cells form the larger inhibitory system. PV cell connectivity develops slowly, reaching maturity only at the end of adolescence; however, the mechanisms controlling the timing of its maturation are not well understood. We discovered that the expression of the neurotrophin receptor p75NTR in PV cells inhibits the maturation of their connectivity in a cell-autonomous fashion, both in vitro and in vivo, and that p75NTR activation in adult PV cells promotes their remodeling and restores cortical plasticity. These results reveal a new p75NTR function in the regulation of the time course of PV cell maturation and in limiting cortical plasticity. 


\section{Introduction}

Within the forebrain, GABAergic interneurons possess the largest diversity in morphology, connectivity, and physiological properties. The large majority of cortical parvalbumin (PV)positive interneurons specifically target the soma and proximal dendrites of pyramidal cells, and have been implicated in synchronizing the firing of neuronal populations and generating gamma oscillations (Cardin et al., 2009; Sohal et al., 2009; Takada et al., 2014), which are important for perception, selective attention, working memory, and cognitive control in humans and rodents (Fries et al., 2001; Howard et al., 2003; Cho et al., 2006; Fries, 2009). PV cells are also involved in experience-dependent refinement of cortical circuits during postnatal development, or critical period plasticity. Indeed, many studies, in particular in sensory cortices, have demonstrated that the timing of critical period plasticity is set by PV cell maturation (Fagiolini and Hensch, 2000; Fagiolini et al., 2004; Di Cristo et al., 2007; Sugiyama et al., 2008; Kobayashi et al., 2015). Several lines of evidence suggest that alterations in PV cell function cause neuronal dysfunctions relevant for clinical features of psychiatric disorders, such as schizophrenia (Cho et al., 2015; Do et al., 2015; Dienel and Lewis, 2018). Furthermore, reducing GABAergic inhibition has been shown to partly restore juvenile-like plasticity in adult visual cortex (Harauzov et al., 2010; Beurdeley et al., 2012), opening the enticing possibility that targeting specific aspects of GABAergic circuits might be exploited as a strategy for promoting rehabilitation in adults.

PV cell function relies on its pattern of connectivity: they innervate hundreds of postsynaptic targets with multiple synapses clustered around the cell body and proximal dendrites. In addition, PV cell connectivity has a prolonged developmental time course, plateauing toward the end of adolescence (Chattopadhyaya et al., 2004). Recent studies have started to explore the molecular players underlying this unique innervation pattern, either in a cell-autonomous (Chattopadhyaya et al., 2007, 2013; Del Pino et al., 2013; Kobayashi et al., 2015) or cell-nonautonomous fashion (Huang et al., 1999; Kohara et al., 2007; Sugiyama et al., 2008). Conversely, the involvement of inhibitory mechanisms in the establishment of PV cell connectivity during development is less clear. In addition, it is unknown whether similar inhibitory molecular mechanisms could be recruited in

Received Nov. 2, 2018; revised Feb. 22, 2019; accepted March 14, 2019.

Author contributions: E.B., B.C., M.L.-J., R.M., P.N.A., P.C., M.G., C.J.-T., E.V., F.A., T.P., and L.B. performed research; E.B., B.C., M.L.-J., R.M., P.C., M.G., C.J.-T., E.V., F.A., T.P., L.B., and G.D.C. analyzed data; E.B. wrote the first draft of the paper; E.B., B.C., M.L.-J., and G.D.C designed research; B.C., M.L.-J., F.A., T.P., and L.B. edited the paper; B.C. and G.D.C. wrote the paper.

This work was supported by the Canadian Institutes of Health Research, Canada Foundation for Innovation, and Canada Research Chair Program to G.D.C. E.B. and M.L.-J. were supported by Fonds de la Recherche du Quebec-Sante fellowship. B.C. was supported by Centre Hospitalier Universitaire Sainte-Justine Foundation. We thank Drs. Graçiela Pineyro (Centre Hospitalier Universitaire Ste. Justine, Montreal), Elsa Rossignol (Centre Hospitalier Universitaire Ste. Justine, Montreal), Nathalie Sanon (Centre Hospitalier Universitaire Ste. Justine, Montreal), Dr. Keith Murai (Centre for Research in Neuroscience, McGill University, Montreal), and Dr. Agustin Anastasia (Instituto de Investigación Médica Mercedes y Martín Ferreyra (Universidad Nacional de Cordoba, Buenos Aires) for their insightful suggestions; Dr. Louis Reichardt (The University of California, San Francisco) for providing reagents; Dr. Vesa Kaartinen (University of Michigan, Ann Arbor, Michigan) for the p75NTR ${ }^{\text {lox }}$ mouse; Dr. Phil Barker (University of British Columbia, Vancouver) for the anti-p75NTR antibody; J.F. Cloutier (Montreal Neurological Institute, Montreal) for the p75NTR KO mice; Josianne Nuñes Carriço and Menna Murrah for technical assistance; Comité Institutionnel de Bonne Pratiques Animales en Recherche, the personnel of the animal facility, and the personnel of the Plateforme Imagerie Microscopique of the Research Center of Centre Hospitalier Universitaire Sainte-Justine for instrumental technical support.

The authors declare no competing financial interests.

*E.B., B.C., and M.L.-J. contributed equally to this work.

Correspondence should be addressed to Graziella Di Cristo at graziella.dicristo@recherche-ste-justine.qc.ca.

https://doi.org/10.1523/JNEUROSCI.2881-18.2019

Copyright $@ 2019$ the authors the adult brain to reduce PV cell connectivity, and in parallel, increase experience-dependent plasticity.

The neurotrophin receptor p75NTR is a multifunctional receptor modulating several critical steps in nervous system development and function, from apoptosis to synaptic plasticity (Lin et al., 2015). In particular, it has been shown that p75NTR interaction with the precursor form of BDNF, proBDNF, or with the prodomain alone, induces growth cone collapse and dendritic spine remodeling in hippocampal excitatory neurons (Anastasia et al., 2013; Giza et al., 2018), and alterations in this process may lead to long-term cognitive dysfunctions (Giza et al., 2018). Because of the difficulty in pinpointing $\mathrm{p} 75 \mathrm{NTR}$ localization in cortical tissue with temporal and single-cell resolution, whether and how p75NTR plays a role on cortical GABAergic circuit development are not clear.

Using RNAscope and Proximity Ligation Essay, here, we show that cortical PV cells expressed p75NTR and that its expression level decreased during the maturation phase of PV cell connectivity. Conditional KO of p75NTR in single PV cells promoted the formation of their perisomatic innervation in cortical organotypic cultures. This effect was mimicked by transfection of a p75NTR dominant negative form in WT PV cells and was rescued by expression of p75NTR in p75NTR ${ }^{-1-}$ PV cells. Conversely, increasing p75NTR signaling strongly reduced PV cell connectivity, both in young and mature organotypic cortical cultures. Further, conditional knockout of p75NTR in GABAergic cells derived from the medial ganglionic eminence promoted the precocious formation of $\mathrm{PV}$ cell perisomatic innervation and perineural nets (PNNs) around PV cell somata in vivo. Finally, we observed that p75NTR activation in PV cells destabilized their innervation, dramatically reduced PNN density and intensity, and promoted ocular dominance plasticity in adult visual cortex.

\section{Materials and Methods}

Mice

Organotypic cortical cultures were prepared from C57BL6 (The Jackson

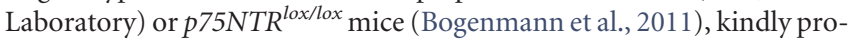
vided by Dr. Vesa Kaartinen. In this mouse, exons $4-6$ of p75NTR, which encode the transmembrane and all cytoplasmic domains, are flanked by two loxP sites. PV_Cre;p75NTR ${ }^{\text {lox } / l o x}$ mice were generated by crossing $p 75 N T R^{f l x}$ with $P V \_C r e$ mice (Hippenmeyer et al., 2005)

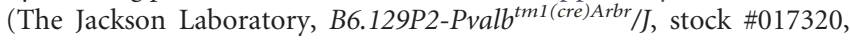
RRID:IMSR_JAX:017320). Cell specificity of Cre-mediated recombination was analyzed by breeding $P V_{-}$Cre with RCE ${ }^{\mathrm{EGFP}}$ mice (Gt (ROSA)

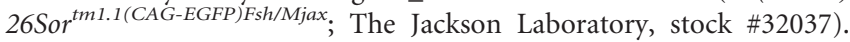
This latter line carries a loxP-flanked STOP cassette upstream of the EGFP gene. Removal of the loxP-flanked STOP cassette by Cre-mediated recombination drives EGFP reporter expression. $p 75 N T R^{l o x} / l o x$ and $p 75 \mathrm{NTR}^{+/+}$mice were analyzed separately in all performed experiments; however, as we did not find any difference between these two genotypes in any experiments ( $t$ test or Mann-Whitney test, $p>0.1$ ), we pooled them together and indicated them as $p 75 N_{T R}{ }^{\text {Ctrl }}$.

\section{Cortical organotypic culture and biolistic transfection}

Slice culture preparation was performed as in Chattopadhyaya et al. $(2004,2013)$ using mice pups of either sex. Briefly, postnatal day 3 (P3) to P5 mice were decapitated, and brains were rapidly removed and immersed in culture medium, containing DMEM (Invitrogen, catalog \#11575-032), 20\% horse serum (Invitrogen, catalog \#26050-088), $1 \mathrm{~mm}$ glutamine (Invitrogen, catalog \#25030-081), $13 \mathrm{~mm}$ glucose (SigmaAldrich, catalog \#G5767), 1 mm CaCl 2 (Sigma-Aldrich, catalog \#C3881), $2 \mathrm{~mm} \mathrm{MgSO}_{4}$ (Sigma-Aldrich, catalog \#M2773), $0.5 \mu \mathrm{m} / \mathrm{ml}$ insulin (Sigma-Aldrich, catalog \#I5500), 30 mm HEPES (Sigma-Aldrich, catalog \#H4034), $5 \mathrm{~mm} \mathrm{NaHCO}_{3}$ (Sigma-Aldrich, catalog \#S5761), and $0.001 \%$ ascorbic acid (Sigma-Aldrich, catalog \#A4544). Coronal brain slices, $400 \mu \mathrm{m}$ thick, were cut with a chopper (Stoelting). Slices were then 
placed on transparent Millicell membrane inserts (Millipore, catalog \#PICM0RG0), usually 2-4 slices/insert, in $30 \mathrm{~mm}$ Petri dishes containing $750 \mu \mathrm{l}$ of culture medium. Finally, they were incubated in a humidified incubator at $34^{\circ} \mathrm{C}$ with a $5 \% \mathrm{CO}_{2}$-enriched atmosphere, and the medium was changed three times per week. All procedures were performed under sterile conditions.

Biolistic transfection was performed as described by Chattopadhyaya et al. (2013). Constructs were incorporated into "bullets" that were made using $1.6 \mu \mathrm{m}$ gold particles (Bio-Rad, catalog \#1652264) coated with $25-30 \mu \mathrm{g}$ of each of the plasmids of interest. When a gold particle coated with multiple constructs enters the neuron, all the constructs are coexpressed within the same cell because they are driven by the same $\mathrm{P}_{\mathrm{G} 67}$ promoter. $\mathrm{P}_{\mathrm{G} 67}-\mathrm{GFP}$ was originally generated by subcloning of a $10 \mathrm{~kb}$ region of Gadl gene promoter by gap repair in front of the GFP coding region in pEGFP (Clontech) (Chattopadhyaya et al., 2004). We have previously shown that this promoter is expressed mostly by PV cells, when transfected in cortical organotypic cultures with a Gene Gun (Chattopadhyaya et al., 2004, 2007, 2013). Bullets were used to transfect organotypic slices using a gene gun (Bio-Rad, catalog \#1652411) at high pressure $(180 \psi)$, and the transfected slices were then incubated for 6-8 $\mathrm{d}$, under the same conditions as described above, before imaging. To label control PV cells, slices were transfected with $\mathrm{P}_{\mathrm{G} 67}$-GFP bullets, whereas p75NTR ${ }^{-1-} \mathrm{PV}$ cells were generated by transfecting slices with both $\mathrm{P}_{\mathrm{G} 67}-\mathrm{GFP}$ and $\mathrm{P}_{\mathrm{G} 67}-\mathrm{Cre}$. Age of cultures was indicated in equivalent postnatal (EP) days; for example, EP10 cultures were prepared at $\mathrm{P} 4$ and then kept $6 \mathrm{~d}$ in vitro.

Recombinant mouse proneurotrophin, proBDNF (wt-proBDNF, 10 $\mathrm{ng} / \mathrm{ml}$, Alomone Labs, catalog \#B-240) and cleavage-resistant, recombinant mouse proBDNF (mut-proBDNF, $10 \mathrm{ng} / \mathrm{ml}$, Alomone Labs, catalog \#B-243) were, respectively, added with the culture medium during the specific time window indicated in Results. To either disrupt or promote the cleavage of endogenous proBDNF induced by tissue plasminogen activator (tPA), the tPA inhibitor peptide, PPACK (50 $\mu \mathrm{M}$, Molecular Innovations, catalog \#PPACK), or the active mouse tPA recombinant protein $(0.6 \mu \mathrm{g} / \mathrm{ml}$, Molecular Innovations, catalog \#MTPA) was, respectively, added within the culture medium. Experimental data were repeated at least twice, using culture batches prepared on different days.

\section{Western blots}

Each sample corresponded to 6 organotypic cultures pooled together. In addition, control (Ctrl) samples were collected from every mouse used for organotypic cultures. Samples were quickly frozen in nitrogen and stored at $-80^{\circ} \mathrm{C}$ until protein extraction procedure. Samples were dissociated in lysis buffer (2 mm EDTA, 1\% Igepal C-630 in TBS, 50 mм Tris, $150 \mathrm{~mm} \mathrm{NaCl}, \mathrm{pH}$ 7.6) containing protease inhibitor (Roche Diagnostics, catalog \#11836153001) and phosphatase inhibitor (Roche Diagnostics, catalog \#04906845001) mixtures at $4^{\circ} \mathrm{C}$, centrifuged $10 \mathrm{~min}$ at $10,000 \times$ $g$ at $4^{\circ} \mathrm{C}$, and the supernatants were dosed with Bradford buffer (Bio-Rad, catalog \#5000006). All samples used for Western blot analysis of a specific protein were run on the same gel. Samples were diluted at the same concentration in Laemmli solution (20\% glycerol, $4 \%$ SDS, $10 \% 2,6$ mercaptoethanol, $0.02 \%$ bromophenol blue in $125 \mathrm{~mm}$ Tris, $\mathrm{pH} 6.8$ ) and boiled at $95^{\circ} \mathrm{C}$ for $5 \mathrm{~min} ; 20 \mu \mathrm{g}$ of protein was migrated on precast gel, $4 \%-15 \%$ acrylamide (Bio-Rad, catalog \#456-1086) at $185 \mathrm{~V}$ for $40 \mathrm{~min}$. The proteins were transferred to a PVDF membrane (Millipore, catalog \#IPVH00010) at $100 \mathrm{~V}$ for $30 \mathrm{~min}$ in transfer buffer (20\% methanol, 192 mu glycine in $25 \mathrm{~mm}$ Tris). The membranes were blocked in 5\% blocking solution (Bio-Rad, catalog \#170-6404) in TBS/T during $2 \mathrm{~h}$ at room temperature. Membranes were then probed with anti-mBDNF (1:200; Santa Cruz Biotechnology, catalog \#sc-546, RRID: AB_630940) and antiGAPDH 1:8000 (mouse monoclonal IgG; Thermo Fisher Scientific, catalog \#AM4300, RRID:AB_2536381) in 5\% blocking solution/TBST $\left(0.1 \%\right.$ Tween in TBS) overnight at $4^{\circ} \mathrm{C}$. The membranes were washed in TBST $(3 \times 15 \mathrm{~min}$ at room temperature) and probed with the following secondary antibodies, anti-mouse-HRP (1:6500, Sigma-Aldrich catalog \#A4416, RRID:AB_258167) and anti-rabbit-HRP (1:10,000, Abcam, catalog \#ab6721, RRID:AB_955447), for $2 \mathrm{~h}$ at room temperature. The membranes were washed in TBST $(3 \times 15 \mathrm{~min})$ and revealed with $\mathrm{ECl}$ (PerkinElmer, catalog \#NEL_103001EA).
Membranes were exposed to Bioflex MSI autoradiography/x-ray film for different time intervals, and only the films that showed easily identifiable, but not saturated, bands for every sample were used for quantification, using ImageJ software (RRID:SCR_003070; http://imagej.nih. gov/ij). Background mean gray value was subtracted, and then values were normalized on GAPDH mean gray value. The average of normalized mean gray value of control experiments was calculated and assigned a value of 1 . The normalized values of the PPACK and tPA treatments were then expressed as the relative of the control samples. Specificity of the anti-BDNF antibody was verified using brain lysates from CaMKII_

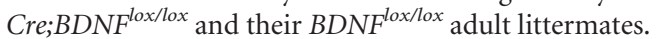

In addition, we tested the following anti-proBDNF antibodies: chicken anti-proBDNF (Millipore, catalog \#AB9042, RRID:AB_2274709), rabbitanti-proBDNF (Alomone Labs, catalog \#ANT-006, RRID:AB_2039758), and guinea-pig-anti-proBDNF (Alomone Labs, catalog \#AGP-032, RRID:AB_2340967). However, in our hands, we could still detect the proBDNF band in lysates from CaMKII_Cre; $B D N F^{\text {lox } / l o x}$ mice; therefore, we could not confirm their specificity and did not use them further in our studies.

\section{Proximity ligation assays (PLAs)}

Mice of both sexes were anesthetized and transcardially perfused with saline $(0.9 \% \mathrm{NaCl})$ followed by $4 \%$ PFA (Sigma-Aldrich, catalog \#P6148) in $\mathrm{PB} 0.1 \mathrm{~m}, \mathrm{pH}$ 7.4. After extraction, brains were incubated in $4 \%$ PFA/PB overnight at $4^{\circ} \mathrm{C}$. Sagittal sections, $60 \mu \mathrm{m}$ thick, were blocked with $10 \%$ horse serum and permeabilized with $0.2 \%$ Triton X-100 at room temperature. Experiments were then performed according to the manufacturer's instructions (Duolink \& PLA Technology, Olink Bioscience). Briefly, sections were incubated with goat-anti p75NTR antibody (1:300, R\&D Systems, catalog \#AF1157, RRID:AB_2298561) in 0.1\% Triton and $5 \%$ horse serum at $4^{\circ} \mathrm{C}$ for $24-36 \mathrm{~h}$. PLA probes anti-goat plus and minus, which are secondary antibodies conjugated with oligonucleotides, were added and incubated for $1 \mathrm{~h}$ at $37^{\circ} \mathrm{C}$ in antibody diluent (Sigma-Aldrich, catalog \#DUO82015). Amplification template oligonucleotides were hybridized to pairs of PLA and circularized by ligation. The hence formed DNA circle was then amplified using rolling circle amplification, and detection of the amplicons was performed using the 624 Duolink in situ detection kits, resulting in red fluorescence signals. All the steps were done exactly as described in the provided manufacturer protocol. Sections were mounted and were analyzed under a $40 \times$ oilimmersion objective using a confocal microscope (Carl Zeiss LSM 780 or Leica Microsystems TCS SP8 X). Distinct bright spots contained within an area of the section designated by the experimenter were counted using an ImageJ macro. Briefly, for each image, we determined a presized ROI that was applied for all images. Then, we performed segmentation by thresholding to generate binary images from each selection. The same threshold was applied to all images acquired during the same imaging session. The number of individual points was quantified using the macro "analyze particles" of ImageJ (RRID:SCR_003070). The "analyze particles" feature was applied with a minimum area of 15 pixels to calculate numbers and total areas of identified objects. Data were exported to Prism (GraphPad, RRID:SCR_002798) for further analysis. For colocalization analysis, we used the Mander's split coefficient to identify the fraction of PLA spots that colocalized with $\mathrm{PV}^{+}$boutons. We confirmed by using the Costes randomization method with 100 iterations that any colocalization was more than expected from randomly distributed fluorophores (ImageJ colocalization analysis with JACop macro) (Bolte and Cordelières, 2006). Each colocalization between PV and PLA signals was further verified manually using Imaris software (Bitplane) by an experimenter blind to the genotype. Each experiment was repeated 3 times. Specificity of anti-p75NTR antibody was tested by performing immunofluorescence staining in an adult p75NTR KO mouse and its WT littermate, kindly provided by Dr. JF Cloutier (data not shown).

\section{Fluorescent multiplex RNAscope}

Mice of both sexes were anesthetized and perfused with saline $(0.9 \%$ $\mathrm{NaCl}$ ) followed by $4 \% \mathrm{PFA} / \mathrm{PB}$, as described above. Brains were dissected and postfixed in $4 \% \mathrm{PFA} / \mathrm{PB}$ for $24 \mathrm{~h}$ at $4^{\circ} \mathrm{C}$, cryoprotected first in $15 \%$ and then in 30\% sucrose in PBS and embedded in OCT. Brain sections 
(15 $\mu \mathrm{m})$ were cut using a cryostat (Leica Microsystems) and mounted on Superfrost Plus Gold Glass Slides (Fisher Scientific, \#22-035-813). Slides were subsequently stored at $-80^{\circ} \mathrm{C}$. Probes against Ngfr mRNA (494261), which codes for p75NTR, and Pvalb mRNA (421931-C2), which codes for PV, as well as all other reagents for ISH and DAPI labeling, were purchased from Advanced Cell Diagnostics. The tissue pretreatment, hybridization, amplification, and detection were performed according to User manual for fixed frozen tissue (Advanced Cell Diagnostics). During RNAscope hybridization, positive probes (catalog \#320881), negative probes (catalog \#320871), and Pvalb/Ngfr probes were processed simultaneously. Briefly, the slides were removed from $-80^{\circ} \mathrm{C}$ and rinsed with PBS to remove OCT. After they were submerged into $1 \times$ Target retrieval solution (catalog \#322000) for $5 \mathrm{~min}$ at $100^{\circ} \mathrm{C}$, and then rinsed in distilled water followed by $100 \% \mathrm{EtOH}$ dip to remove access water. Protease III (catalog \#322337) was added to each section and incubated for $30 \mathrm{~min}$ at $40^{\circ} \mathrm{C}$ followed by washing in distilled water. For detection, probes were added to each section and incubated for $2 \mathrm{~h}$ at $40^{\circ} \mathrm{C}$. Unbound probes were subsequently washed away by rinsing slides in $1 \times$ wash buffer (catalog \#310091). AMP reagents (AMP1 catalog \#320852, AMP2 catalog \#320853, AMP3 catalog \#320854, AMP4A cata$\log \# 320855$, C1 probes-Alexa-488; C2 probes-Atto-550) were added to each section and incubated for as per the manufacturer's instructions, and washed in wash buffer for $2 \mathrm{~min}$. Sections were stained with DAPI (catalog \#320858) for $30 \mathrm{~s}$, and then mounted with Prolong Gold Antifade Mountant (Invitrogen, catalog \#P36961). Images were acquired with a DMI8 microscope (Leica Microsystems), using an HC PL APO $40 \times / 0.85$ DRY objective, voxel size: $0.163 \mu \mathrm{m} \times 0.163 \mu \mathrm{m} \times 0.346 \mu \mathrm{m}$, and deconvolved using Huygen's express deconvolution option. The figures represent the maximum projection of acquired $z$ stack. This experiment was performed using tissue from three different mice for each age point ( 2 and 8 postnatal weeks).

\section{Immunohistochemistry}

Cortical organotypic cultures were fixed in $4 \% \mathrm{PFA} / \mathrm{PB}, \mathrm{pH} 7.4$, overnight at $4^{\circ} \mathrm{C}$, then washed in PBS $\left(3 \times 10^{\prime}\right)$, freeze-thawed in $30 \%$ sucrose/PBS, washed in PBS $\left(3 \times 10^{\prime}\right)$, and immunostained as previously described (Chattopadhyaya et al., 2004).

Mice of both sexes were perfused with saline $(0.9 \% \mathrm{NaCl})$ followed by $4 \% \mathrm{PFA} / \mathrm{PB}, \mathrm{pH}$ 7.4. Brains were then removed and postfixed overnight at $4^{\circ} \mathrm{C}$ in the same fixative solution, cryoprotected in $30 \%$ sucrose/PBS for 1-2 d, and then frozen in Tissue Tek (Leica Microsystems, catalog \#3801480); 40- $\mu \mathrm{m}$-thick brain slices were obtained using a cryostat (Leica Microsystems). The following primary antibodies were used: NeuN (mouse monoclonal, 1:400, Millipore; catalog \#MAB377, RRID: AB_2298772), PV (mouse monoclonal, 1:5000, Swant, catalog \#235, RRID:AB_10000343), PV (rabbit polyclonal, 1:5000, Swant, catalog \#PV25, RRID:AB_10000344), vesicular GABA transporter (vGAT, rabbit polyclonal, 1:400, Synaptic Systems, catalog \#131003, RRID:AB_887869), gephyrin (mouse monoclonal, 1:500, Synaptic Systems, catalog \#147021, RRID:AB_2232546). Briefly, brain slices were incubated in a blocking solution, containing 10\% NGS (Invitrogen, catalog \#10000C) and 1\% Triton in PBS for $2 \mathrm{~h}$ at room temperature, followed by incubation with the primary antibodies (specific concentrations described above) in $5 \%$ NGS, $0.1 \%$ Triton in PBS for $24-48 \mathrm{~h}$ at $4^{\circ} \mathrm{C}$. Slices were then washed in PBS $\left(3 \times 10^{\prime}\right)$, incubated with the appropriate Alexa555-conjugated or Alexa633-conjugated antibodies (Invitrogen, 1:400) in 5\% NGS, $0.1 \%$ Triton in PBS for $2 \mathrm{~h}$ at room temperature, washed again in PBS $(3 \times$ $10^{\prime}$ ), and mounted in Vectashield (Vector Lab, catalog \#H-1000) before imaging.

\section{PNN labeling}

To label PNNs, brain slices were incubated in a solution of biotinconjugated lectin Wisteria floribunda (WFA) (10 $\mu \mathrm{g} / \mathrm{ml}$; Sigma-Aldrich, catalog \#L1516, RRID:AB_2620171) for $1.5 \mathrm{~h}$ at room temperature in 5\% NGS/0.1\% Triton/PBS followed by Alexa 568-conjugated streptavidin (1:500; Invitrogen, catalog \#S-11226, RRID:AB_2315774) for $2 \mathrm{~h}$ at room temperature in $5 \%$ NGS $/ 0.1 \%$ Triton/PBS. Tissue was then washed $3 \times 10^{\prime}$ in PBS and mounted in Vectashield mounting medium before imaging.
Analysis of PV cell innervation in cortical organotypic cultures Previous studies have shown that the basic features of maturation of perisomatic innervation by PV cells onto NeuN-positive neurons (which represent mostly pyramidal cells) (Chattopadhyaya et al., 2004) are retained in cortical organotypic cultures. In organotypic cultures, PV cells start out with very sparse and simple axons, which develop into complex, highly branched arbors in the subsequent 4 weeks with a time course similar to that observed in vivo (Chattopadhyaya et al., 2004). We have previously shown that the vast majority of GFP-labeled boutons in our experimental conditions most likely represent presynaptic terminals (Chattopadhyaya et al., 2007, 2013; Di Cristo et al., 2007).

For each experimental group, we took care to acquire an equal number of PV cells localized in layer 2/3 and 5/6. On average, we acquired only one PV cell from each successfully transfected organotypic culture. Confocal images of the PV cell axon arbors were taken in the first $150 \mu \mathrm{m}$ from the PV cell soma using a $63 \times$ glycerol objective (NA 1.3, Leica Microsystems) and a Leica Microsystems SPE or a Leica Microsystems SP8 confocal microscope. Analysis of PV cell perisomatic innervation was performed as described previously (Chattopadhyaya et al., 2013), using Neurolucida software (MBF, RRID:SCR_001775). Briefly, neuron somata were identified by NeuN immunofluorescence, and the axon of PV cells was traced in 3D. Only innervated NeuN-positive cells were included in this analysis. The following parameters were analyzed for each PV cell: (1) perisomatic bouton density, (2) axonal terminal branching around innervated somata, and (3) percentage of NeuN-positive somata innervated by a PV cell. In our 3D Sholl analysis, Sholl spheres with a $1 \mu \mathrm{m}$ increment from the center of a NeuN-positive soma were used to quantify PV cell axon terminal branch complexity and bouton density around the NeuN-positive soma. Axon branch complexity around a single NeuN-positive soma was quantified by the average number of intersections between the PV cell axon and the Sholl spheres in the first $9 \mu \mathrm{m}$ from the center of the NeuN-positive soma. We choose $9 \mu \mathrm{m}$ as the limiting radius for Sholl spheres because it approximates the average NeuN-positive soma diameter. Between 10 and 15 NeuN-positive somata were analyzed for each PV cell. To quantify the fraction of NeuNpositive somata potentially innervated by a PV cell axon, we divided the number of NeuN-positive neurons contacted by at least one GFP positive-bouton by the total number of NeuN-positive cells, in a confocal stack (at least 2 stacks per PV cell). We measured NeuN-positive cell density and found it to be invariant with respect to the different manipulations. All data were first averaged per PV cell; thus, statistical analysis was done using the number of PV cells as " $n$."

\section{Imaging and analysis of immunolabeling in vivo}

For the analysis of PV, vGAT, and PNN expression in minipumpimplanted brains, sections were processed in parallel, and all images were acquired the same day using identical confocal parameters. Confocal images (Leica Microsystems, either SPE or SP8 confocal microscope) were acquired using either a $20 \times$ water-immersion objective (NA 0.7; Leica Microsystems) or a $63 \times$ glycerol objective (NA 1.3; Leica Microsystems). For each animal, we acquired two confocal stacks in layer 5 in both hemispheres (infused, ipsilateral vs noninfused, contralateral). Data were obtained from 3 or 4 brain sections per animal. $z$ stacks were acquired with a $1 \mu \mathrm{m}$ step, exported as TIFF files, and analyzed using ImageJ software (RRID:SCR_003070). Briefly, PV, vGAT, or PNN perisomatic rings (between 7 and 10 in each stack) were outlined, and the mean gray values were measured, after background subtraction. Background was determined by measuring mean gray values in at least three different areas (ROI), where immunolabeling was absent, in the same focal plane where PV, vGAT, or PNN perisomatic rings were selected.

For the analysis of $\mathrm{PV}^{+} /$gephyrin ${ }^{+}$puncta, confocal images (Leica Microsystems, SP8) were acquired using a $63 \times$ glycerol objective (NA 1.3; Leica Microsystems). We acquired one confocal stack with a $0.3 \mu \mathrm{m}$ step in cortical layer 5 from 3 or 4 different brain sections per animal. Stacks were exported as TIFF files, and puncta colocalization was analyzed using Neurolucida software.

All analysis was done by operators blind to the mouse genotype or/and to the specific treatment. 


\section{Minipump implant and monocular deprivation}

Adult ( $>$ P100) mice were implanted with osmotic minipump under isoflurane anesthesia. Minipumps (model 1007D; flow rate $0.5 \mu \mathrm{l} / \mathrm{h}$; Alzet) were filled with mut-proBDNF $(1 \mu \mathrm{g} / \mathrm{ml}$ in filtered PBS, Alomone Labs) or vehicle solution and connected to a cannula (gauge 30) implanted directly in the primary visual cortex ( $2.5 \mathrm{~mm}$ lateral to the midline, $2.5 \mathrm{~mm}$ anterior to $\lambda$ ).

For electrophysiological analysis, a group of animals were monocularly deprived through eyelid suturing $2 \mathrm{~d}$ after the implant of the minipump, and then recorded for $3 \mathrm{~d}$ after. Subjects with even minimal spontaneous eyelid reopening were excluded from the study. For perisomatic GABAergic bouton density and PNN studies, a second group of animals was perfused $5 \mathrm{~d}$ after minipump implant.

\section{In vivo electrophysiology}

After $3 \mathrm{~d}$ of monocular deprivation, animals were sedated with isoflurane and anesthetized with urethane (i.p. injection; $1.5 \mathrm{~g} / \mathrm{kg} ; 20 \%$ solution in saline; Sigma-Aldrich), then placed in a stereotaxic frame. Body temperature was maintained at $37^{\circ} \mathrm{C}$. A hole was drilled in the skull, corresponding to the binocular portion of the primary visual cortex (binocular area Oc1B), contralateral to the deprived eye. Dexamethasone $(2 \mathrm{mg} / \mathrm{kg}$ ) was administered subcutaneously to reduce secretions and edema, and saline was periodically infused to prevent dehydration. Eyes were covered with a thin layer of silicone oil to avoid corneal opacities. Recordings were made using silicon microprobes (16 channels, NeuroNexus Technologies a2x2-tet-3 mm-150-121) inserted into the cortex 3.0-3.2 mm from the $\lambda$ point. Signals were acquired using Cheetah 5 (Neuralynx) and analyzed with custom software in MATLAB (The MathWorks).

\section{Visual stimulation}

Stimuli were generated in MATLAB using the Psychophysics Toolbox (RRID:SCR_002881) extensions and displayed with gamma correction on a monitor (Sony Trinitron G500, $60 \mathrm{~Hz}$ refresh rate, $32 \mathrm{~cd} / \mathrm{m} 2$ mean luminance) placed $20 \mathrm{~cm}$ from the mouse, subtending $60^{\circ}-75^{\circ}$ of visual space.

\section{Visual-evoked potentials (VEPs)}

VEPs were recorded as described by Porciatti et al. (1999). We measured contralateral to ipsilateral ratio (C/I) of VEP amplitude to measure ocular dominance plasticity. Extracellular signal was filtered from 1 to 275 $\mathrm{Hz}$. VEPs in response to square wave patterns with a spatial frequency of 0.06 cycles per degree and abrupt phase inversion ( $1 \mathrm{~Hz}$ temporal period) were evaluated in the time domain by measuring the $\mathrm{P} 1$ peak-to-baseline amplitude and latency. Computer-controlled mechanical shutters were used to collect data from each eye.

\section{Single units}

For single-unit recording, extracellular signal was filtered from 0.6 to 6 $\mathrm{kHz}$. Sampling rate was $33 \mathrm{kHz}$. Spiking events were detected online by voltage threshold crossing, and waveforms of $1 \mathrm{~ms}$ were acquired around the time of threshold crossing. To improve isolation of units, recordings from groups of four neighboring sites (tetrode) were linked, so that each spike was composed by 4 waveforms. Then waveforms were processed using the OffLine Sorter software (Plexon). Drifting sinusoidal gratings were used as visual stimuli ( $1.5 \mathrm{~s}$ duration, temporal frequency of $2 \mathrm{~Hz}, 12$ directions, 6 spatial frequency: $0.01,0.02,0.04,0.08,0.16,0.32$ cycles per degree). Stimulation was repeated five times per eye, with stimulus conditions randomly interleaved, and two gray blank conditions (mean luminance) were included in all stimulus sets to estimate the spontaneous firing rate.

The average spontaneous rate for each unit was calculated by averaging the rate over all blank condition presentations. Responses at each orientation and spatial frequency were calculated by averaging the spike rate during the $1.5 \mathrm{~s}$ stimulus presentations and subtracting the spontaneous rate. The preferred stimulus was determined finding the combination of spatial frequency and orientation that maximize the response, independently for each eye. Ocular dominance index (ODI) was calculated as follows: ODI $=($ respContra - respIpsi $) /($ respContra + respIpsi $)$, where resp is the response evoked by the preferred stimulus, and Contra and
Ipsi are contralateral and ipsilateral eye, respectively. Experiments were done by operators blind to the genotype.

\section{In vivo optical imaging}

Optical imaging experiments were performed as in Groleau et al. (2014). Briefly, mice were anesthetized with urethane $(1.25 \mathrm{~g} / \mathrm{kg}$, i.p.). Core body temperature was maintained at $37^{\circ} \mathrm{C}$ using a feedback-controlled heating pad (Harvard Apparatus), and electrocardiogram (FHC) was continuously monitored with subdermal electrodes. The visual cortex was imaged through the skull: an imaging chamber was placed over both hemispheres, glued on the skull, filled with agarose (1\%), and sealed with a coverslip.

Stimulation. Visual stimulation was provided using VPixx and presented by an LCD projector on a screen placed at a distance of $20 \mathrm{~cm}$ in front of the mouse eyes (subtending $150 \times 135^{\circ}$ of visual angle). To assess visuotopy and characterize maps and connectivity in V1, we used a continuous stimulation paradigm, where $2^{\circ}$ thick light bars were periodically shifted horizontally (to obtain elevation maps) or vertically (to obtain azimuth maps) over a dark background at a frequency of $0.15 \mathrm{~Hz}$. These relative retinotopic maps were used to assess several structural and functional parameters within V1. To examine the functional properties of $\mathrm{V} 1$ neurons, episodic full-field sine wave grating stimuli $\left(270^{\circ}\right)$ were presented during $2 \mathrm{~s}$ and spaced by a blank presentation lasting $18 \mathrm{~s}$ intervals (mean luminance $75 \mathrm{~cd} / \mathrm{m}^{2}$ ). The amplitude of the hemodynamic responses was measured as a function of contrast and spatial frequency selectivity. Five contrasts $(6 \%, 12 \%, 25 \%, 50 \%$, and $90 \%)$ and seven spatial frequencies $(0.01,0.025,0.05,0.12,0.24,0.32$, and 0.48 cycle per degree) were used to determine contrast sensitivity and spatial frequency selectivity, respectively.

Image acquisition. The cortex was illuminated at $545 \mathrm{~nm}$ to adjust the focus of the camera and at $630 \mathrm{~nm}$ to record the intrinsic signals. Optical images were recorded using a 12-bit CCD camera (1M60, Dalsa) driven by the Imager 3001 system (Optical Imaging) and fitted with a macroscopic lens (AF Micro Nikon, $60 \mathrm{~mm}, 1: 2: 8 \mathrm{D}$ ). Frames of $512 \times 512$ pixels were acquired at a rate of $4 \mathrm{~Hz}$, giving a spatial resolution of 28 $\mu \mathrm{m} /$ pixel. The acquisition was sustained for $10 \mathrm{~min}$ during the continuous stimulation paradigm. During episodic stimulation, frames were acquired for $20 \mathrm{~s}$ for every contrast and spatial frequency tested. An average of 10 repetitions was used to obtain a good signal-to-noise ratio.

Data analysis. Optical intrinsic signal (OIS) data were analyzed with MATLAB (The MathWorks). For each pixel of the cortex, a Fourier transform was applied on temporal signals collected during continuous stimulation. Fourier phase and amplitude were generated for each frequency and used to map the retinotopy and perform quantification. The amplitude of neuronal activity was used to generate the "neuronal activation" map. In parallel, the phase at the stimulus frequency was related to the delay to activate the receptive field and was associated with the relative retinotopic position. The "retinotopic" map was obtained by multiplying the amplitude and phase maps. ROIs located in the occipital cortex were manually delineated in the activation maps for each hemisphere. The area of $\mathrm{V} 1$ was calculated from the ROI borders. The shape of the ROI was fitted to an ellipse with MATLAB, and the ratio of length of the two main axes of the ellipse determined (height/width) was calculated to measure the "ovality index." The ratio of the number of the phases detected in the retinotopic maps over $2 \pi$ (i.e., the range of the phases displayed) was used to estimate the "apparent visual field" (i.e., the proportion of the activated visual field represented in V1). The difference between the phase of each pixel and its surrounding pixels was calculated on the phase map to evaluate the "scatter index." Fourier amplitude at the stimulus frequency and second harmonic were used to evaluate the population receptive field size of the underlying neurons (neurons within a ROI respond to a range of visual field locations and the region of the visual space that stimulates this local neuronal activity is called population receptive field).

The hemodynamic responses obtained during episodic stimulation were used for the functional analysis of the neuron features. The contrast and spatial frequency tuning curves for each pixel of V1 were established from the amplitude of the negative peak of the hemodynamic response. The spatial frequency producing the strongest hemodynamic response 
was calculated for each pixel. For each animal, the results of each trial were pooled and an asymmetric Gaussian curve was fitted on the normalized values. Curves that did not meet the $p<0.05$ and $r^{2} \geq 0.700$ were not used. The optimal spatial frequency was defined as the spatial frequency producing the strongest response. The visual acuity was measured using a linear fit. The curves of amplitude as a function of the contrast were fitted with a Naka-Rushton function to determine the contrast evoking $50 \%$ of the maximum response.

\section{Experimental design and statistical analysis}

Mice were assigned randomly to each experimental group. Data analysis was performed by operators that were blind of the treatment/genotype. Data were expressed as mean \pm SEM, unless otherwise specified in the legends. Normality tests were performed for all data analyzed. Differences between two groups were assessed with the Student's unpaired $t$ test for normally distributed data or with the Mann-Whitney Rank Sum test for not normally distributed data. Differences between multiple groups were assessed with one-way ANOVA. Statistical analysis was performed using Prism 8.0 (GraphPad, RRID:SCR_002798). No animal was excluded from the analysis.

\section{Results}

\section{Cortical PV cells express p75NTR during development and in} the adult brain

The temporal and cellular localization of p75NTR in cortical neurons has been an object of debate and discrepancy (Holm et al., 2009; Giza et al., 2018), likely due to low protein expression levels, especially in the adult brain, and suboptimal antibody sensitivity. To overcome these technical challenges, we used two novel experimental strategies. First, we used RNAscope multiplex fluorescent ISH (Advanced Cell Diagnostics), a novel RNA ISH technology that allows single-molecule detection (Wang et al., 2012), to label simultaneously the mRNAs coding for p75NTR (gene name: $N g f r$ ) and PV (gene name: Pvalb) in brain slices (Figs. $1 A, B, 2)$. Importantly, we found cortical neurons coexpressing both mRNAs 2 weeks after birth (Fig. $1 A, B$ ), in contrast to basal ganglia wherein the mRNAs coding for p75NTR and PV were expressed by clearly nonoverlapping populations (Fig. 2E). Second, we used a modified version of the PLA as described by Telley et al. (2016), coupled with PV immunolabeling. PLA is a very sensitive technique of amplification used to detect a low level of protein expression or protein-protein interaction in tissues, using which we observed unprecedented clear and definite signal for p75NTR in PV cell somata and putative boutons in visual cortex of adult mice (P60) (Fig. 1C). To control for PLA signal specificity, we crossed $p 75 N T R^{\text {lox/lox }}$ mice with mice expressing Cre recombinase under the control of the PV promoter ( $P V \_C r e$ mice) (Hippenmeyer et al., 2005) and compared the PLAmediated p75NTR labeling in $p 75 N_{T R}^{\text {lox/lox }}$ versus PV_Cre; p75NTR ${ }^{\text {lox/lox }}$ littermates (Fig. $1 C-F$ ). We found that p75NTR signal was dramatically reduced in PV cells in the conditional $\mathrm{KO}$ mice (Fig. 1E), demonstrating the specificity of our approach. Surprisingly, we also observed that the total P75NTR signal showed an $\sim 60 \%$ reduction in conditional $\mathrm{KO}$ mice compared with control littermates (Fig. $1 F$ ), suggesting that PV cells expressed a large proportion of p75NTR protein in the adult visual cortex.

Next, we asked whether p75NTR protein expression in PV cells was developmentally regulated in visual cortex. We found that p75NTR expression, identified using the PLA assay, in PV cells was significantly reduced between P14 and P26 (Fig. 3A-C; unpaired $t$ test with Welch's correction). Compared with its expression in adult visual cortex, we observed similar localization pattern of p75NTR protein in PV cell somata and in putative perisomatic synapses at both P14 and P26. Similarly, we observed a similar decrease in the expression of the mRNA coding for
p75NTR between P14 and adult mice, using RNAscope (data not shown). Overall, these data suggest that cortical PV cells express p75NTR and that this expression is developmentally regulated.

\section{p75NTR downregulation during the first postnatal weeks induce the formation of exuberant PV cell innervation in cortical organotypic cultures}

Because the developmental downregulation of p75NTR was inversely correlated with the maturation of PV cell innervation during the same time period in visual cortex (Chattopadhyaya et al., 2004), we hypothesized that higher p75NTR levels may hinder the formation of PV cell synapses. To test this hypothesis, we used cortical organotypic cultures where we could label and manipulate isolated PV cells by driving GFP and/or Cre expression with a previously characterized promoter $\left(\mathrm{P}_{\mathrm{G} 67}\right)$ (Chattopadhyaya et al., 2004, 2007, 2013; Di Cristo et al., 2007). In organotypic cultures, PV cells start out with very sparse and simple axons, which develop into complex, highly branched arbors in the subsequent 3 weeks with a time course similar to that observed in vivo (Chattopadhyaya et al., 2004).

In the postnatal cortex, p75NTR is not expressed exclusively by PV cells (Fig. 3) (Bracken and Turrigiano, 2009); thus, to investigate whether p75NTR in PV cells plays a role in their maturation, we knocked out p75NTR selectively in PV cells by transfecting $P_{G 67}-C r e / G F P$ in organotypic cultures from $p 75 N^{2} R^{\text {lox/lox }}$ mice (Bogenmann et al., 2011) to generate $\mathrm{p}^{2} 5 \mathrm{NTR}^{-1-} \mathrm{PV}$ cells in an otherwise WT background (Fig. 4). PV cells were transfected with $P_{G 67}-C r e / G F P$ from EP10 (cultures prepared at $\mathrm{P} 4+$ 6 DIV) and fixed at EP18. p75NTR ${ }^{-1-}$ PV cells contacted more neuronal somata (identified by NeuN labeling) and formed more axonal branching and perisomatic boutons compared with agematched control $p 75 N T R^{l o x / l o x} \mathrm{PV}$ cells, which were transfected with $P_{G 67}-G F P$ alone (Fig. $4 A-C, E$ ). p75NTR ablation in single $\mathrm{PV}$ cells during the peak of perisomatic bouton proliferation (EP16-EP24) also increased bouton density and terminal branching without increasing the percentage of contacted neurons (Fig. 4C-E). These data suggest that p75NTR expression constrains the maturation of PV cell innervation in a cellautonomous manner.

To further test this hypothesis, we investigated whether transfecting WT PV cells with a mutant form of p75NTR lacking the intracellular death domain and acting as dominant negative (p75 DDD) (Charalampopoulos et al., 2012; Lin et al., 2015) could affect their innervation (Fig. $5 A, B$ ). PV cells transfected with $75 \Delta \mathrm{DD}$ showed more complex perisomatic innervation (Fig. $5 A, B, E$ ), which was indistinguishable from those formed by p75NTR $^{-1-}$ PV cells (Fig. $5 B, C, E$ ).

It is conceivable that Cre-mediated removal of exons $4-6$ in $N g f r$ might also delete intronic sequences that are important for PV cell synaptic development. To confirm that the deletion of p75NTR was indeed responsible for the exuberant perisomatic innervation of $\mathrm{p}^{2} 5 \mathrm{NTR}^{-1-} \mathrm{PV}$ cells, we performed a rescue experiment by introducing p75NTR cDNA in $\mathrm{p}^{2} 5 \mathrm{NTR}^{-1-} \mathrm{PV}$ cells. In particular, we cotransfected PV cells in organotypic cultures prepared from $p 75 N T R^{\text {lox } / l o x}$ mice with either $P_{G 67}-C r e /$ GFP (to generate p75NTR ${ }^{-1-}$ PV cells) or $\mathrm{P}_{\mathrm{G} 67}-\mathrm{Cre} / \mathrm{GFP} / \mathrm{p} 75 \mathrm{wt}$ (to reexpress $\mathrm{p} 75 \mathrm{NTR}$ in $\mathrm{p} 75 \mathrm{NTR}^{-1-} \mathrm{PV}$ cells). The perisomatic innervation formed by reintroduction of p75NTR in ${\text { p } 75 N^{-1-}}^{-1} \mathrm{PV}$ cells was not significantly different from those formed by WT cells (Fig. 5A,D,E).

Together, these data demonstrate that p75NTR expression in cortical PV cells regulates the maturation of their connectivity by constraining the formation of their perisomatic innervation. 

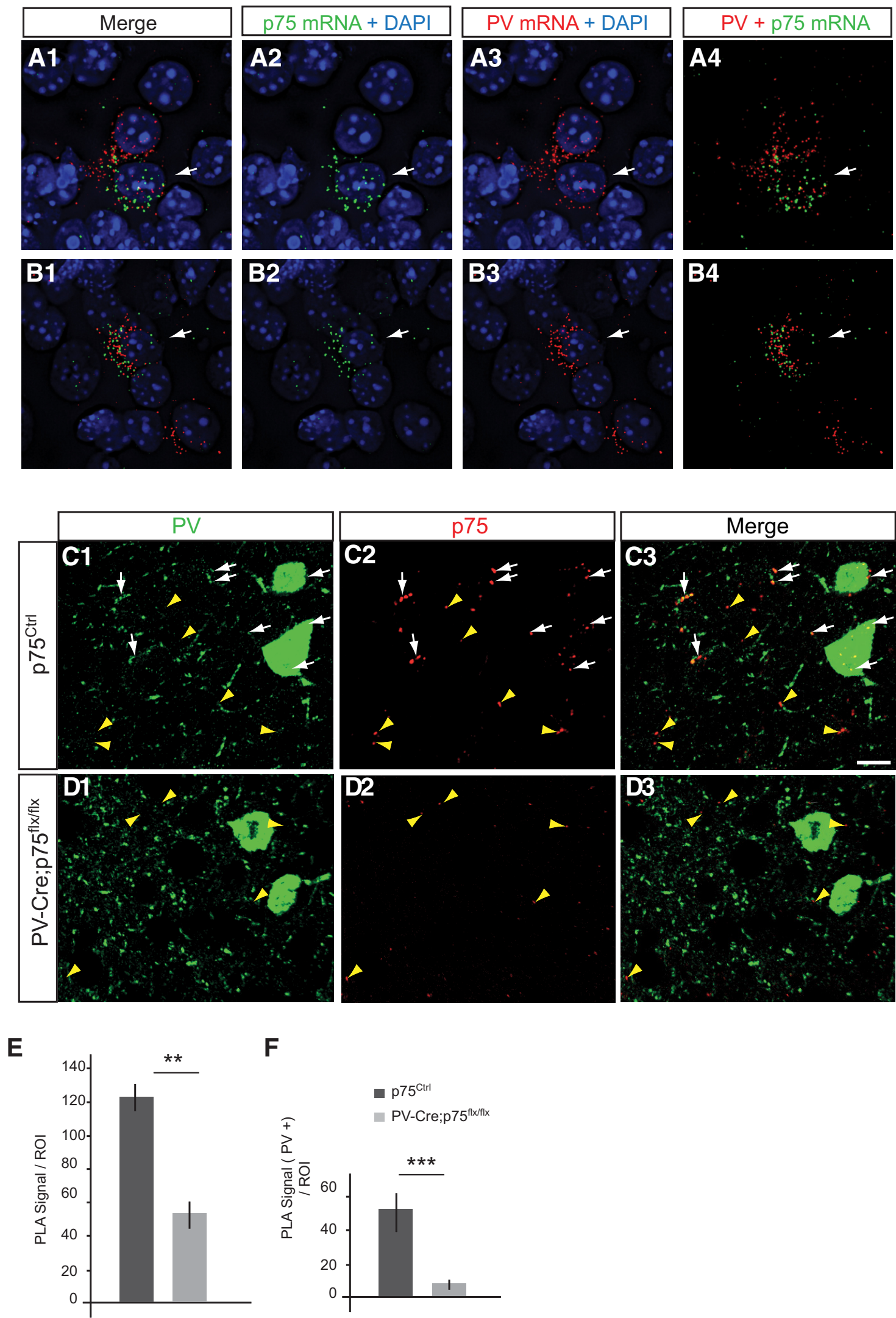

Figure 1. A subset of PV cells express p75NTR mRNA and protein. $\boldsymbol{A}, \boldsymbol{B}$, Images from coronal brain section of P14 mouse hybridized with PV (Pvalb) and p75 (Ngfr) probes using fluorescent multiplex RNAscope technology. p75 mRNA (A2, B2; green dots) is detected in cells expressing PV mRNA (A3, B3; red dots). White arrows indicate p75 and PV signals around the same nucleus, identified by DAPI staining (blue). C, D, Cortical slices from $p 75 N_{T R} R^{f x / f x}(\boldsymbol{C})$ or PV_Cre;p75NTR ${ }^{f x / f x}(\boldsymbol{D})$ P60 mice coimmunostained with PV (C1, D1; green) and p75NTR using PLA (C2, D2; red dots). White arrows indicate PLA signals that colocalize with PV signals (C1-C3, D1-D3). The p75NTR signal can be observed in PV cell boutons. Yellow arrowheads indicate PLA signals without PV colocalization (C1-C3,D1-D3). Scale bar, $10 \mu \mathrm{m}$. E, Quantification of PLA signal reveals a significant reduction of total PLA signals per ROl in PV_Cre;p75NTR ${ }^{\text {flx } / f x}$ compared with WT littermates.ttest, df = $8, t=5.391,{ }^{* *} p=0.004$. F, Further, PLA signals that colocalized with PV labeling decrease significantly in PV_Cre;p75NTR ${ }^{f f f f x}$ compared with WT littermates. $t$ test, df $=8, t=8,728,{ }^{* * *} p=0.0006$. 

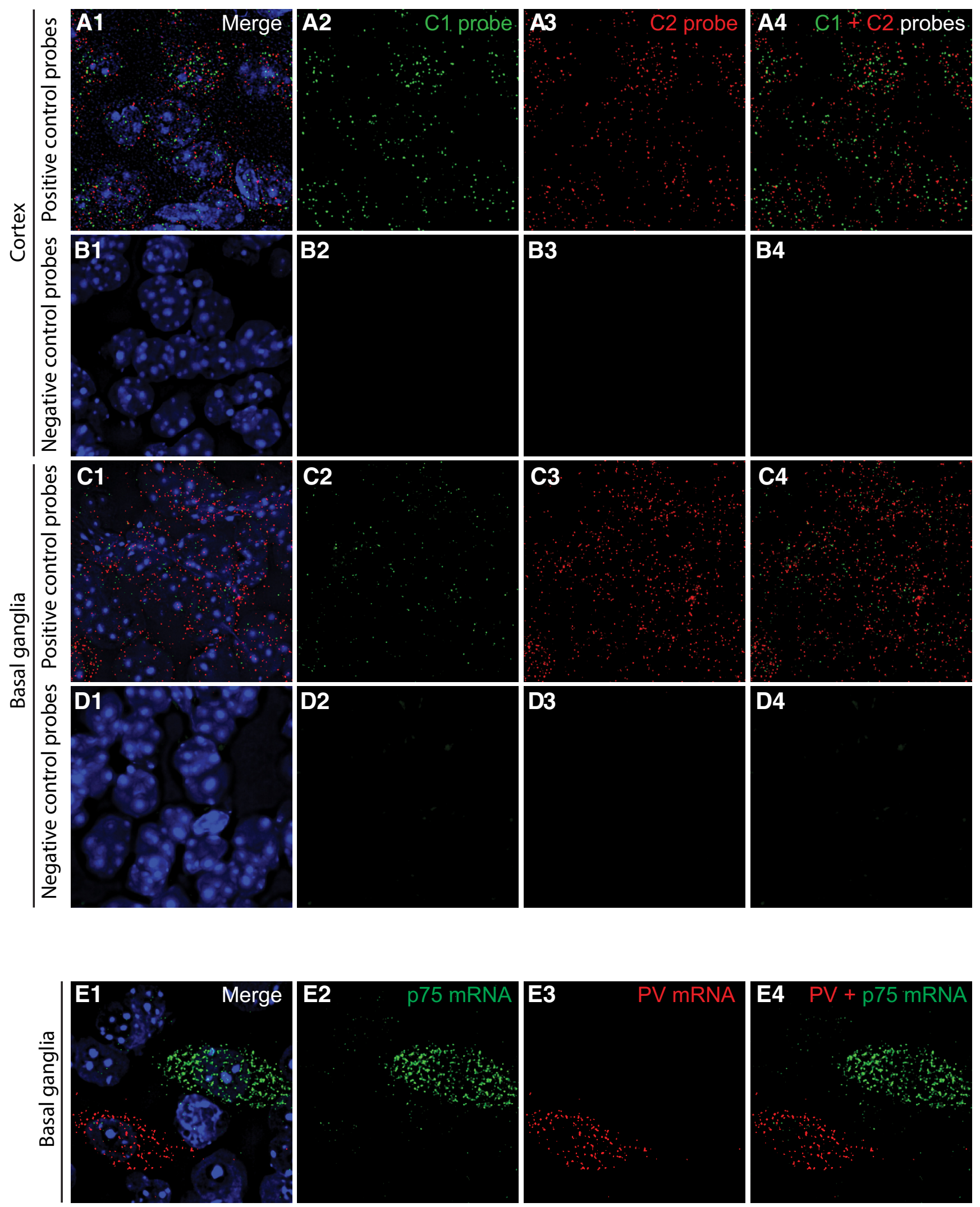

Figure 2. Controls for RNAscope probe specificity. $A-D$, Validation of the RNAscope Fluorescent Multiplex assay using positive and negative control probes, provided by the manufacturer. Coronal brain slices were hybridized with the RNAscope positive control probes $(\boldsymbol{A}, \boldsymbol{C})$ and negative control probes $(\boldsymbol{B}, \boldsymbol{D})$. Images were taken from the cortex $(\boldsymbol{A}, \boldsymbol{B})$ and the basal ganglia $(\boldsymbol{C}-\boldsymbol{E})$. $\boldsymbol{E}$, In the basal ganglia, cells express exclusively either PV mRNA or p75 mRNA. 

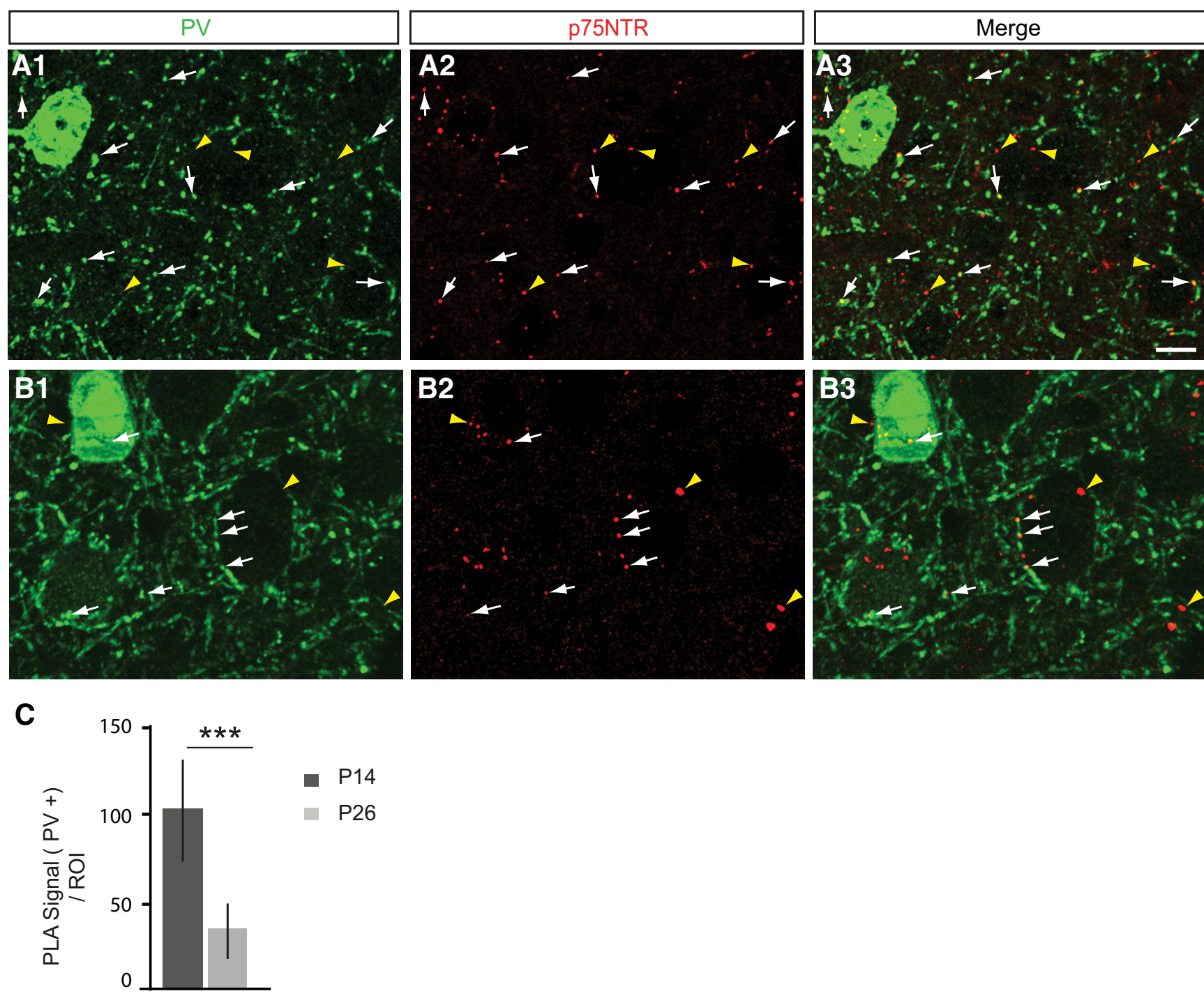

Figure 3. p75NTR expression in cortical PV cells decreases during the first postnatal month. $\boldsymbol{A}, \boldsymbol{B}$, Cortical slices from P14 (A) and P26 (B) WT mice immunostained with PV to label PV cells (A1, $B 1$; green) and PLA-mediated labeling for p75NTR (A2, B2; red dots, henceforth indicated in figures as p75). White arrows indicate PLA signals that colocalize with PV signals (A1-A3, B1-B3). Yellow arrowheads indicate PLA signals without PV colocalization (A1-A3, B1-B3). At both ages, p75NTR signal can be found in both PV-positive cell somata and putative boutons. Scale bar, 10 $\mu \mathrm{m}$. C, Quantification of p75NTR PLA intensity in PV cells at different postnatal ages shows a significant decline of p75NTR signal in PV cells and boutons between P14 and P26 (unpaired $t$ test with Welch's correction, $\left.\mathrm{df}=22.44, t=7.642,{ }^{* * *} p<0.0001\right) . n=4$ animals for each age point.

Increased p75NTR activation inhibits the formation of PV cell innervation in cortical organotypic cultures

p75NTR-mediated signaling can be strongly activated by both proneurotrophins or their prodomain alone (Yang et al., 2009; Rauskolb et al., 2010; Dieni et al., 2012; Anastasia et al., 2013; Zanin et al., 2017). Activation of p75NTR by proBDNF has been shown to reduce excitatory synapse density in hippocampal pyramidal neurons (Woo et al., 2005; Yang et al., 2014), to promote excitatory synapse elimination in the postnatal visual cortex (Winnubst et al., 2015) and at the developing neuromuscular junction (Je et al., 2013). To investigate whether proBDNF affects the development of inhibitory PV cell connectivity, we treated developing organotypic cultures either with a WT recombinant form (wt-proBDNF, $10 \mathrm{ng} / \mathrm{ml}$ ) or a cleavage-resistant mutant form of proBDNF (mut-proBDNF; $10 \mathrm{ng} / \mathrm{ml}$ ) from EP18-EP24. wt-proBDNF did not significantly affect $\mathrm{PV}$ cell perisomatic bouton number (Fig. $6 A, B, E$ ) but induced a significant increase of the terminal axonal branching complexity formed by PV cells around their targets (Fig. $6 F$ ). It is likely that proBDNF was at least partially cleaved by extracellular plasmin and metalloproteases, thus affecting the local, relative level of mBDNF and proBDNF (Pang et al., 2004). On the other hand, PV cells treated with mut-proBDNF contacted less than half of the NeuNpositive somata compared with age-matched controls, onto which they formed fewer boutons and terminal axonal branching (Fig. 6C,E-G). This effect was not secondary to neuronal death because neuron density (based on NeuN immunostaining) was not altered compared with control or wt-proBDNF-treated slices, even after $6 \mathrm{~d}$ of treatment (Ctrl: $104 \pm 13$; wt-proBDNF: $174 \pm 10$; and mut-proBDNF: $135 \pm 15 \times 10^{3}$ pyramidal cells/ $\mathrm{mm}^{3} ; n=6$ Ctrl slices, $n=6$ wt-proBDNF-treated slices, $n=8$ mut-proBDNF-treated slices; one-way ANOVA, $p>0.1$ ). To investigate whether the effects of mut-proBDNF on PV cell innervation were specifically mediated by p75NTR activation, we knocked out p75NTR from single PV cells in organotypic cultures prepared from $\mathrm{p} 75 \mathrm{NTR}{ }^{\text {lox/lox }}$ mice and simultaneously treated them with mut-proBDNF. We found that $\mathrm{p}^{2} \mathrm{NTR}{ }^{-1-}$ PV cells were insensitive to mut-proBDNF treatment; indeed, 

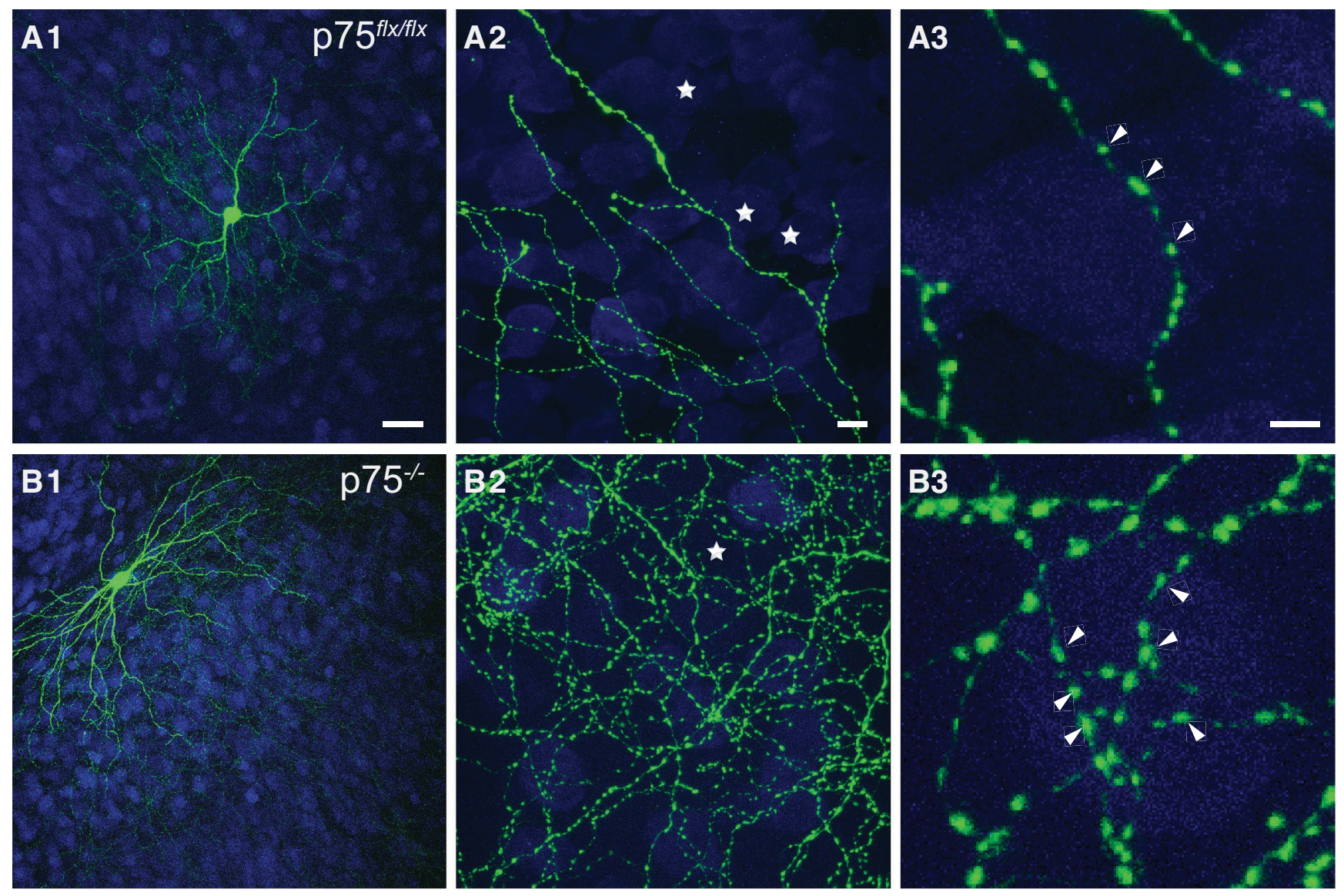

C

\section{Bouton density}

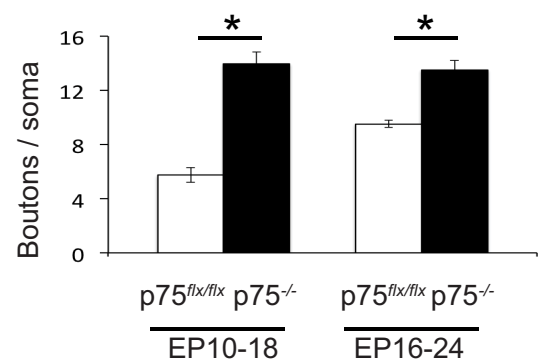

D Terminal branching

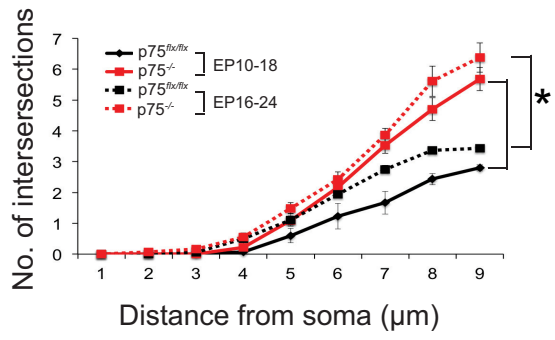

E \% innervated somata

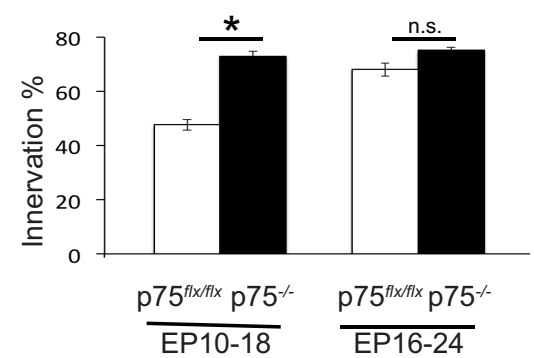

Figure 4. Cre-mediated inactivation of p75NTR in single PV cells induces the formation of more complex innervations. $A$, Control PV cell transfected with $P_{g 67}-G F P$ in EP18 organotypic cultures from $p 75^{f(x / f x}$ mice shows immature perisomatic innervation with one terminal, axonal branching, and small boutons. B, PV cells transfected with $P_{667} 7^{-C(r e / G F P f r o m ~ E P 10-E P 18 ~(p 75 ~}{ }^{-1}$ P PV cells) show exuberant perisomatic innervation characterized by multiple terminal axonal branches (B2) bearing numerous clustered boutons (B3; arrowheads) around neuronal somata (NeuN immunostaining, blue). Stars indicate NeuN-positive somata that are not innervated. $\boldsymbol{A} \mathbf{3}, \boldsymbol{B} \mathbf{3}$, From regions in $\boldsymbol{A} \mathbf{2}$ and $\boldsymbol{B} \mathbf{2}$. Scale bars: $\boldsymbol{A} \mathbf{1}, \boldsymbol{B} \mathbf{1}, 50 \mu \mathrm{m} ; \boldsymbol{A} \mathbf{2}, \boldsymbol{B} \mathbf{2}, 5 \mu \mathrm{m} ; \boldsymbol{A} \mathbf{3}, \boldsymbol{B} \mathbf{3}, 3 \mu \mathrm{m}$. Perisomatic bouton density $(\boldsymbol{C})$, terminal branching $(\boldsymbol{D})$, and percentage of innervated cells $(\boldsymbol{E})$ of p $75^{\mathrm{fl} / \mathrm{ffl} x}$ and p75 ${ }^{-I-}$ PV cells transfected at EP10 $-E P 18$ or EP16-EP24 (C) EP10 -EP18: unpaired $t$ test, df $=13, t=$ 8.835, $p<0.0001$, EP16-EP24: Mann-Whitney test, $p=0.0022$. D, EP10 -EP18: Mann-Whitney test: at 5, $6 \mu \mathrm{m}: p=0.0037$; at 7-9 $\mu \mathrm{m}: p=0.0003$; EP16 -EP24: unpaired $t$ test: at $6 \mu \mathrm{m}$ : $\mathrm{df}=10, t=2.513, p=0.0307 ;$ at $7 \mu \mathrm{m}: \mathrm{df}=10, t=4.908, p=0.0006$; at $8 \mu \mathrm{m}: \mathrm{df}=10, t=5.065, p=0.0005 ;$ at $9 \mu \mathrm{m}: \mathrm{df}=10, t=6.063, p=0.0001 . E$, EP10 - EP18: unpaired $t$ test,

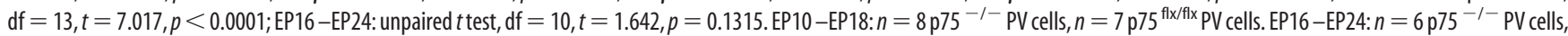
$n=6 \mathrm{p} 75^{\mathrm{fl} / \mathrm{flx}} \mathrm{PV}$ cells. * indicate $p<0.05$.

they formed significantly more complex innervations compared with both control and mut-proBDNF-treated $\mathrm{p} 75 \mathrm{NTR}^{\text {lox/lox }} \mathrm{PV}$ cells (Fig. $6 A, D$ ). The results suggest that specific activation of p75NTR strongly inhibits the formation of PV cell innervation during postnatal development.

Several studies suggested that mature BDNF (mBDNF) and prodomain $\mathrm{BDNF}(\mathrm{pBDNF})$ are the most abundant moieties in the adult brain, whereas proBDNF is abundant during early development, in particular during the first postnatal month (Rauskolb et al., 2010; Dieni et al., 2012; Anastasia et al., 2013; Yang et al., 2014). We thus asked whether altering endogenous levels of proBDNF and mBDNF affected the establishment of PV cell innervation in the first postnatal weeks. To address this question, we altered the activity levels of tPA because tPA-mediated activa- 

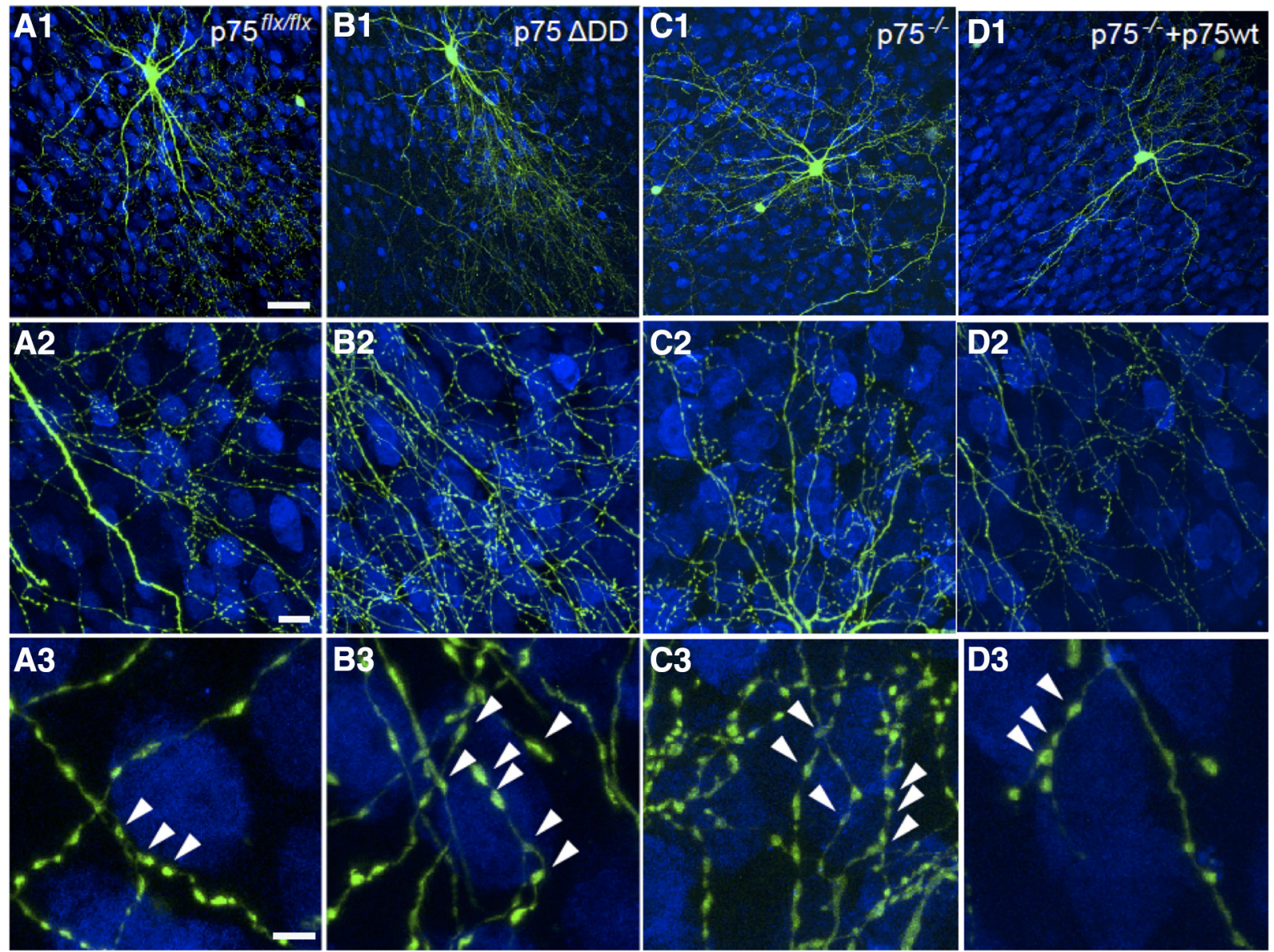

E

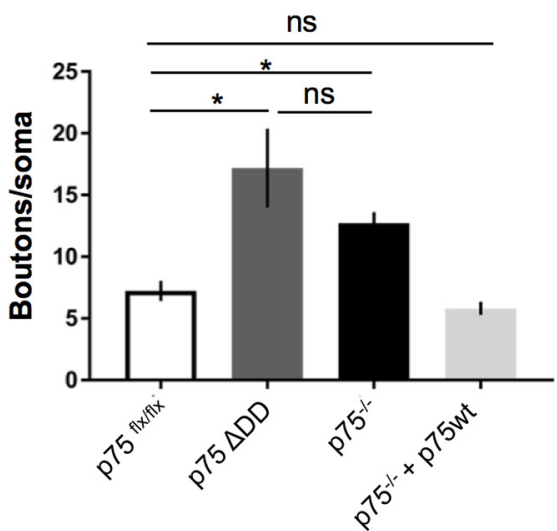

F Terminal branching

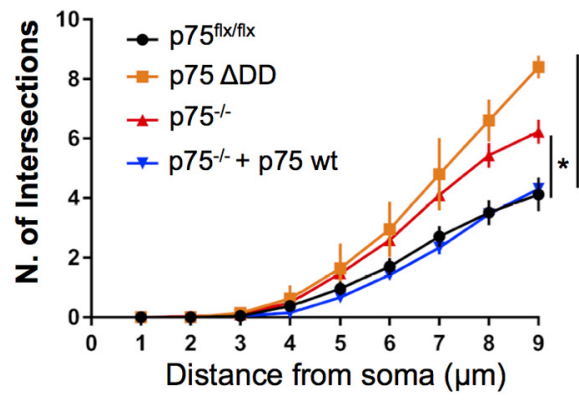

\section{G \% innervated somata}

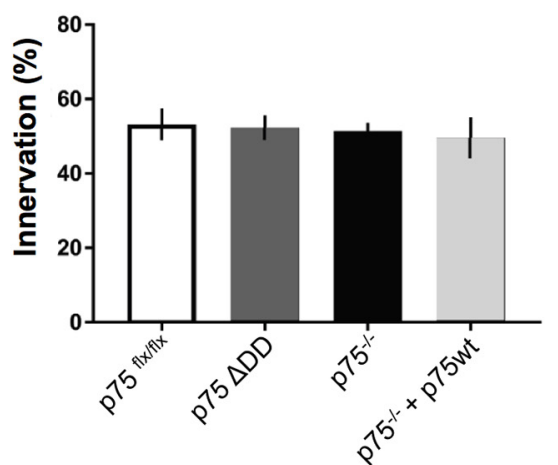

Figure 5. p75NTR $\triangle D D$ mimics, whereas p75NTRwt rescues, the innervation phenotype of p75NTR ${ }^{-/-}$PV cells. $A$, Control PV cell transfected with $P_{g 67}-G F P$ in EP24 organotypic cultures from p $75^{f l x / f l x}$ mice. $B$, PV cells transfected with $P_{G 67}$-GFP and a dominant negative mutant form of p75NTR, p75NTR $\Delta D D$, from EP16-EP24 (p75 ${ }^{-1-}$ p75 $\Delta$ DD PV cells) shows more complex perisomatic innervation characterized by multiple terminal axonal branches (B2) bearing numerous clustered boutons (B3; arrowheads) around NeuN-positive somata (blue). $\boldsymbol{C}$, PV cells transfected with

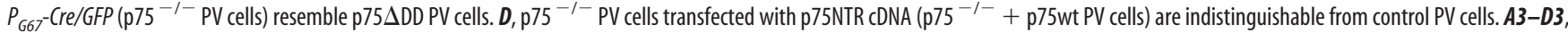
Regions in A2-D2. Scale bars: A1-D1, $50 \mu \mathrm{m} ; A$ 2-D2, $10 \mu \mathrm{m} ; A$ 3-D3, $5 \mu \mathrm{m}$. $\boldsymbol{E}$, Perisomatic boutons density (one-way ANOVA, $F_{(3,26)}=8.854, p=0.0003$ ). $\boldsymbol{F}$, Terminal branching (one-way ANOVA, at $7 \mu \mathrm{m}: F_{(3,26)}=4.529, p=0.0110$; at $8 \mu \mathrm{m}: F_{(3,26)}=10.15, p=0.0001$; at $\left.9 \mu \mathrm{m}: F_{(3,26)}=16.05, p<0.0001\right)$. G, Percentage of innervated cells (one-way ANOVA, $F_{(3,26)}=1.303$, $p=0.3101)$. PV cells: $n=9 \mathrm{p} 75^{\mathrm{flx} / \mathrm{flx}}, n=5 \mathrm{p} 75 \Delta \mathrm{DD}, n=9 \mathrm{p} 75^{-1-} \mathrm{PV}$ cells, $n=7 \mathrm{p} 75^{-1-}+\mathrm{p} 75 \mathrm{wt} .{ }^{*}$ indicate $p<0.05$.

tion of plasmin is one of the main molecular mechanisms responsible for the activity-dependent cleavage of proBDNF into mBDNF in the extracellular space (Pang et al., 2004; Schwartz et al., 2011). To modulate tPA activity levels, we added to the cul- ture medium either PPACK (50 $\mu \mathrm{M})$, a tPA-inactivating peptide, or tPA itself $(0.6 \mu \mathrm{g} / \mu \mathrm{l})$ from EP10-EP18, when PV cell axonal arborization and synaptic innervation are still quite immature (Chattopadhyaya et al., 2004). First, we sought to quantify 


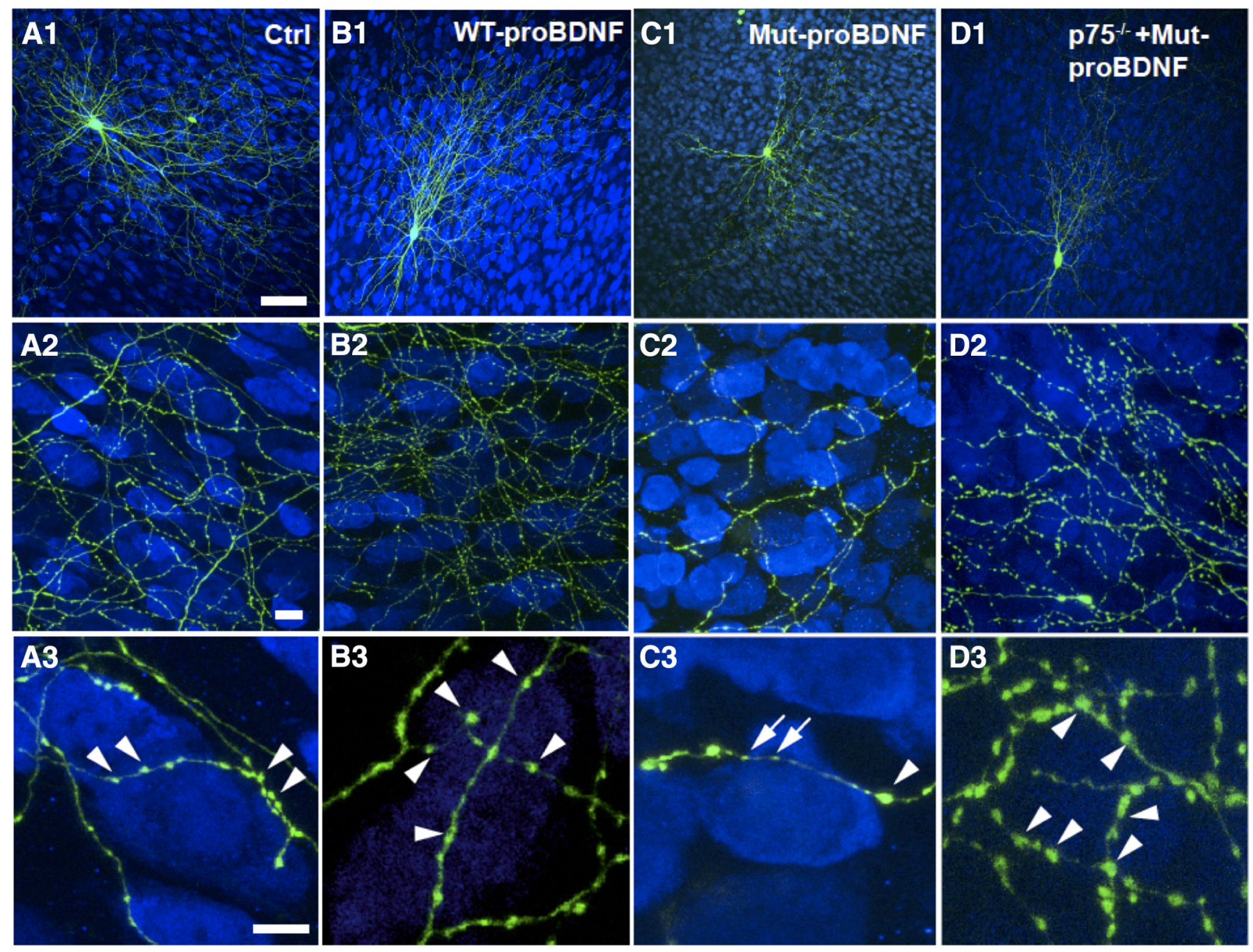

E Bouton density

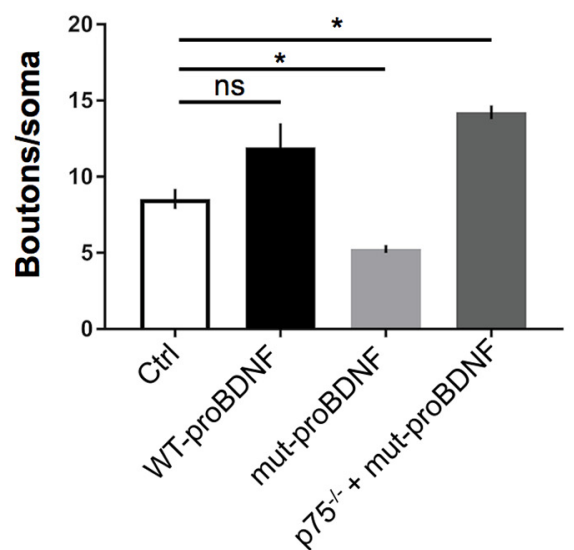

F Terminal branching

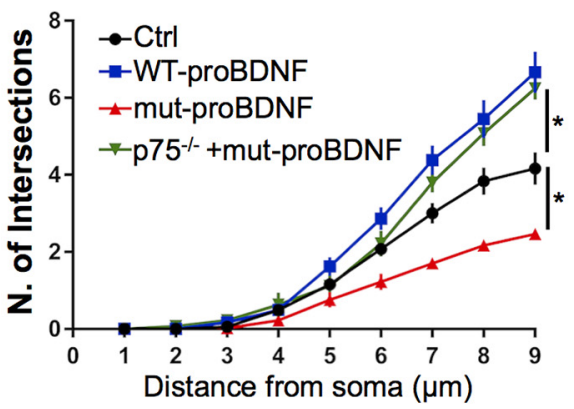

G \% innervated somata

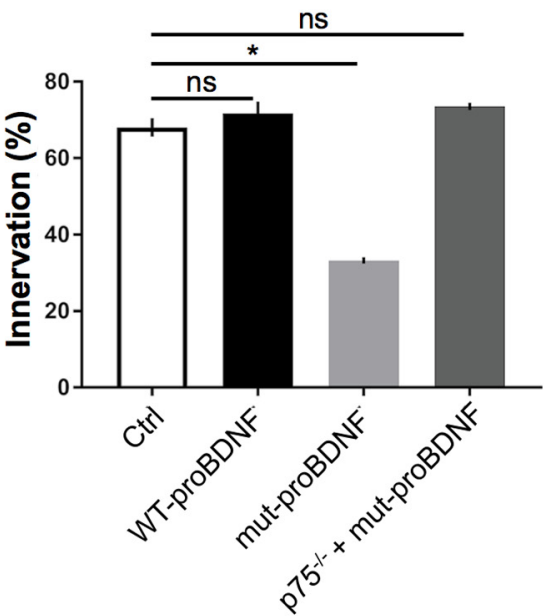

Figure 6. mut-proBDNF-mediated activation of p75NTR in PV cells during their maturation phase impairs the development of their innervations. $\boldsymbol{A}$, Control PV cell (A1, green represents Ctrl) at EP24 with exuberant innervation field characterized by extensive branching contacting the majority of potential targets, dense boutons along axons (A2), and terminal branches with prominent and clustered boutons ( $\boldsymbol{A}$; ; arrowheads) around NeuN-positive somata (blue). $\boldsymbol{B}$, PV cell treated with wt-proBDNF from EP16 -EP24 shows overall similar axon size (B1) and perisomatic bouton density (B3; arrowheads); however, axonal branching appears slightly increased (B3). C, PV cell treated with mut-proBDNF shows a reduction both in percentage of innervated cells (C2) and perisomatic innervation (C3). Boutons appear more irregular with some large (arrowheads) and many smaller ones (arrows). D, p75NTR ${ }^{-1-}$ PV cells treated with mut-proBDNF are undistinguishable from

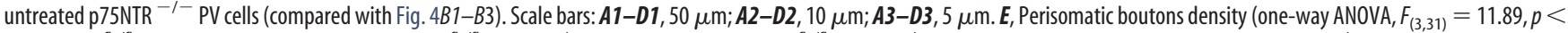

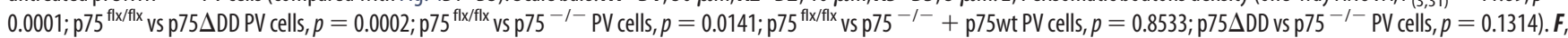
Terminal branching (one-way ANOVA, at $7 \mu \mathrm{m}: F_{(3,31)}=15.27, p<0.0001 ;$ at $8 \mu \mathrm{m}: F_{(3,31)}=14.10, p<0.0001 ;$ at $\left.9 \mu \mathrm{m}: F_{(3,31)}=21.08, p<0.0001\right)$. Both WT PV cells treated with wt-proBDNF and p75NTR $^{-I-}$ cells treated with mut-proBDNF show significantly higher sholl intersection numbers than Ctrl PV cell at 8 and $9 \mu \mathrm{m}(p<0.05)$, whereas PV cells (Figure legend continues.) 


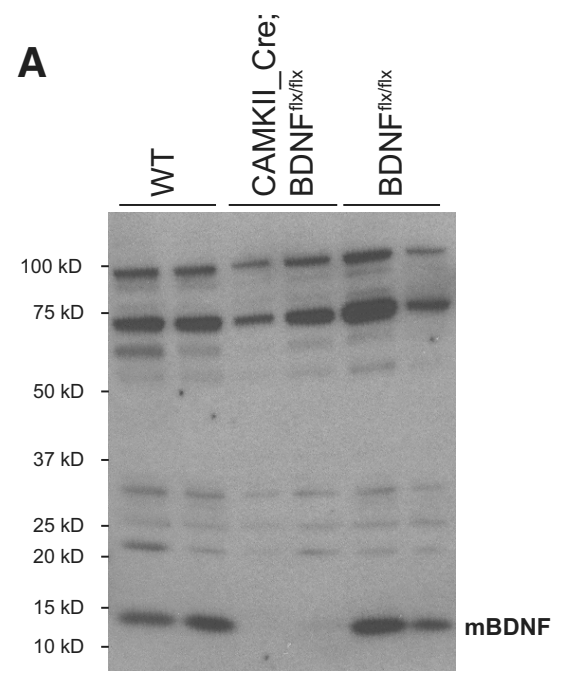

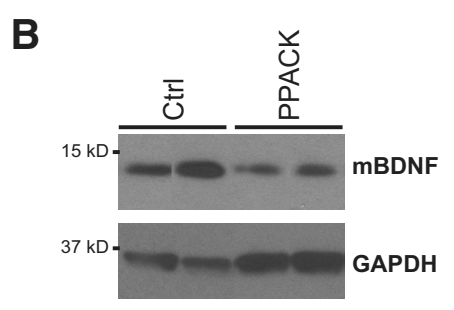

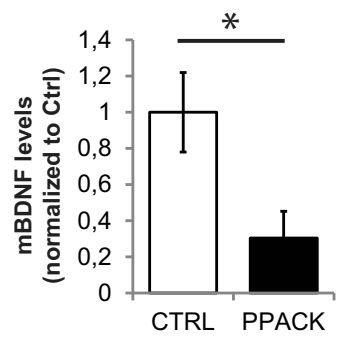

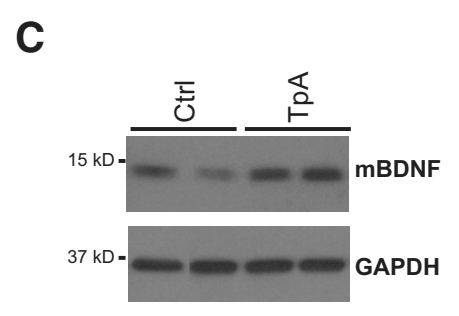

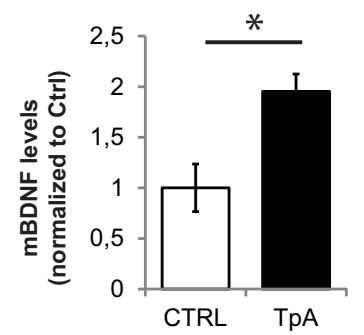

Figure 7. Blocking or increasing tPA activity during early postnatal development reduces and increases mBDNF levels in organotypic cultures, respectively. $\boldsymbol{A}$, Full Western blot of mBDNF expression in brain samples from adult wt, CaMKIl;BDNF ${ }^{\text {flox/flox }}$, and BDNF ${ }^{\text {flox/flox }}$ mice. Each lane represents a different mouse brain. The 14 kDa band, corresponding to mBDNF, is not detectable when Bdnf is deleted in pyramidal cells (CaMKII-Cre;BDNF ${ }^{\text {lox/lox }}$ conditional K0 mouse), thus confirming the specificity of the antibody we used for these experiments (1:200, Santa Cruz Biotechnology, N20:sc-546). B, C, Western blot analysis of mBDNF (14 kDa) of cortical organotypic cultures treated with either PPACK (B) or tPA (C) for 8 d, from EP10 -EP18. Each lane represents a single sample, which is constituted by 6 organotypic cultures pooled together. PPACK treatment significantly decreases mBDNF levels $(\boldsymbol{B})$, whereas tPA increases them $(\boldsymbol{C})$. Unpaired $t$ test, ${ }^{*} p<0.05(\boldsymbol{B})$ $n=3 \mathrm{Ctrl}$ and $n=3$ PPACK-treated samples. $C, n=5 \mathrm{Ctrl}$ and $n=4$ tPA-treated samples. Samples are from different mice.

whether and how endogenous mBDNF and proBDNF levels were affected by these treatments by Western blot. While we confirmed the specificity of the anti-mBDNF antibody using brain lysates of $B d n f K O$ (Fig. $7 A$ ), we tested several commercial proBDNF antibodies, but, in our hands, they could still detect a $32 \mathrm{kDa}$ band in brain lysates from $B d n f K O$ mice (for details on tested antibodies, see Materials and Methods); thus, we could only quantify mBDNF levels. As predicted, we found that treatment with PPACK reliably induced a significant reduction (Fig. $7 B$ ), whereas tPA significantly increased mBDNF protein level (Fig. 7C), suggesting that tPA may indeed regulate extracellular level of mBDNF in this developmental time window. Consistent with this hypothesis, PV cells in PPACK-treated cultures showed simpler innervation fields (Fig. $8 A, B, E-G$ ), whereas tPA addition drastically increased the complexity of PV cell axonal arborization compared with control, age-matched PV cells by increasing bouton density, terminal axonal branching, and percentage of innervated targets (Fig. $8 A, C, E-G$ ).

Because mBDNF-mediated TrkB signaling is a potent regulator of GABAergic cell maturation (Huang et al., 1999; Kohara et al., 2007; Hong et al., 2008), it is possible that these effects might be solely due to alteration of mBDNF level, independently of p75NTR activation. To address this question, we reasoned that, if the effects of tPA application on PV cell innervation were mediated not only by an increase in mBDNF but also by a decrease in proBDNF-mediated p75NTR signaling, then treatment with mut-proBDNF would reverse them. Supporting this prediction, we found that simultaneously treating organotypic cultures with

$\leftarrow$

(Figure legend continued.) treated with mut-proBDNF show significantly reduced sholl intersection numbers than Ctrl PV cell at 7,8, and $9 \mu \mathrm{m}(p<0.01)$. G, Percentage of innervated cells of the four experimental groups (one-way ANOVA, $F_{(3,31)}=69.65, p<0.0001$ ). ${ }^{*}$ indicate $p<$ 0.05. $n=9$ Ctrl PV cells, $n=11$ wt-proBDNF-treated PV cells, $n=8$ mut-proBDNF-treated PV cells, $n=7$ mut-proBDNF-treated p75 ${ }^{-1-}$ PV cells.
tPA and mut-proBDNF rescued completely the effects of tPAonly application (Fig. 8D,E-G).

In summary, these results suggest that p75NTR activation, possibly mediated by endogenous proBDNF, can strongly inhibit the formation of cortical PV cell innervation during the first postnatal weeks.

\section{p75NTR regulates the timing of the maturation of PV cell connectivity in vivo}

Our results show that p75NTR expression in PV cells declines during the maturation phase of PV cell connectivity and that removing p75NTR is sufficient to promote, while activating p75NTR inhibits, the formation of PV cell innervation. We next asked whether P75NTR plays a role in the maturation of PV cell connectivity in vivo.

In PV_Cre mouse cortex, Cre expression is very specific to PV cells; however, it starts after P10 and does not plateau until weeks later (Hippenmeyer et al., 2005), well after the maturation of PV cell connectivity (Chattopadhyaya et al., 2004). Thus, to reduce p75NTR expression in PV cells before the peak of the maturation of PV cell connectivity, we generated Nkx2.1_Cre;p75NTR ${ }^{\text {lox/lox }}$ mice. Nkx2.1 is expressed in GABAergic precursors originating from the medial ganglionic eminence, which include PV- and somatostatin-expressing interneurons (Xu et al., 2008). We quantified the putative perisomatic synapses formed by PV cells, identified by the juxtaposition of PV and gephyrin, a scaffolding protein present in the postsynaptic sites of GABAergic synapses, in the visual cortex of P14 Nkx2.1_Cre;p75NTR ${ }^{\text {lox/lox }}$ mice compared with their control littermates (Fig. 9A,B). Both the density of $\mathrm{PV}^{+}$gephyrin ${ }^{+}$puncta and the percentage of perisomatic showing juxtaposed gephyrin were significantly increased (Fig. $9 C, D)$ in the conditional $\mathrm{KO}$ mice.

One important indication of PV cell maturation is the appearance of PNNs, which are specialized extracellular matrix structures enwrapping the soma and primary dendrites of mature cortical PV cells (Pizzorusso et al., 2002; Morishita et al., 2015). In 

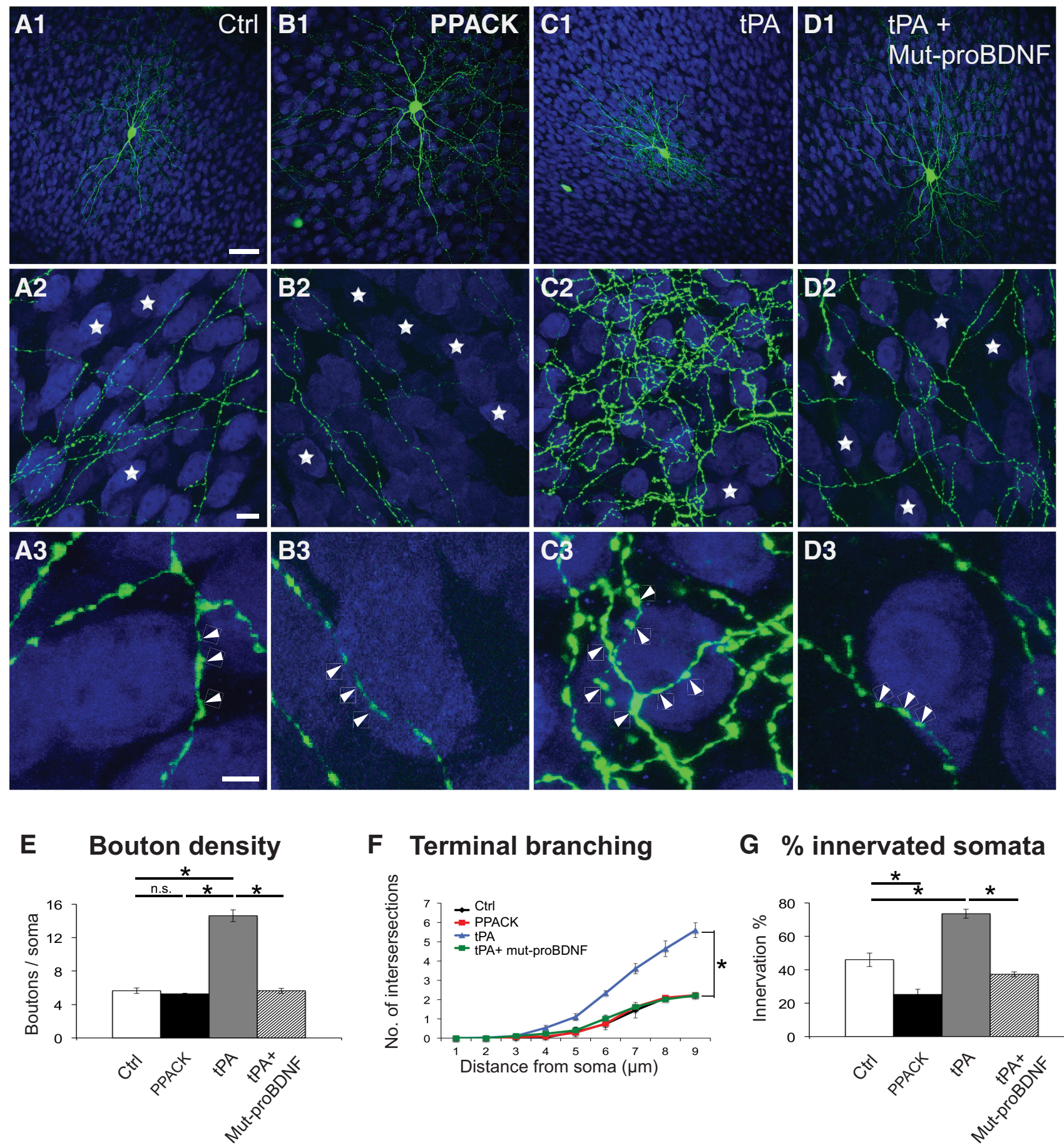

F Terminal branching

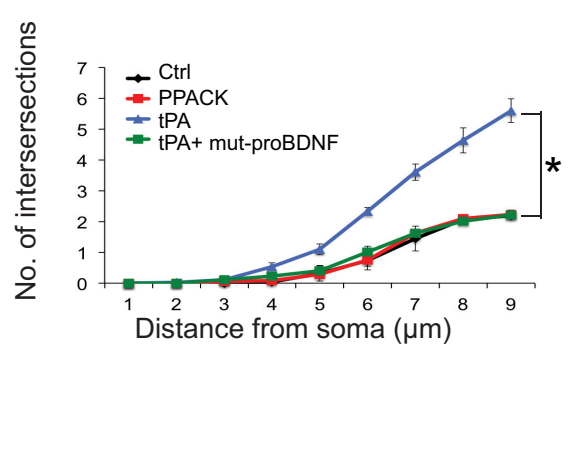

G \% innervated somata

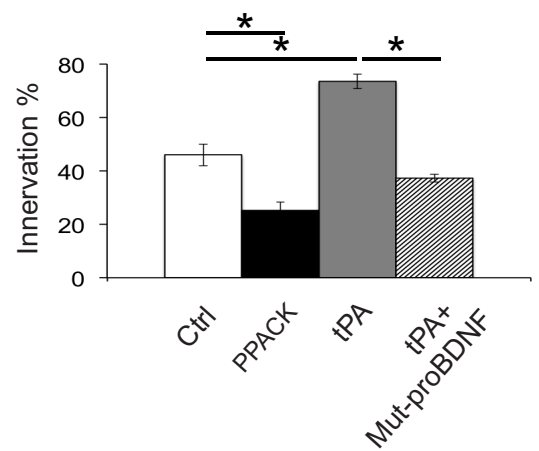

Figure 8. Modulation of tPA activity affects the formation of PV cell innervations during early postnatal development. $\boldsymbol{A}$, Control EP18 PV cell ( $\boldsymbol{A} \mathbf{1}$, green represents Ctrl). $\boldsymbol{B}$, PV cell treated with the tPA inhibitor PPACK from EP10 -EP18 shows simpler axonal arborization, contacting less potential targets (B2, blue represents NeuN-positive somata). C, PV cell treated with tPA in the same time window shows a very complex axonal arbor (C2) and an increase in both terminal branching and perisomatic boutons ( $\mathbf{C}$, arrowheads) compared with control cells (A2, A3). D, PV cell treated simultaneously with TPA and mut-proBDNF shows axonal branching and perisomatic innervation more similar to those formed by PV cell treated with mut-proBDNF alone, suggesting that the effects

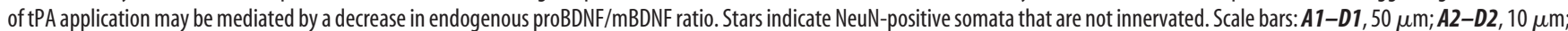
A3-D3, $5 \mu \mathrm{m}$. E, Perisomatic boutons density (one-way ANOVA, $F_{(3,20)}=121.2, p<0.0001$ ). $\boldsymbol{F}$, Terminal branching (one-way ANOVA, at $5 \mu \mathrm{m}: F_{(3,20)}=5.692, p=0.0055 ;$ at $6 \mu \mathrm{m}: F_{(3,20)}=$ $19.67, p<0.0001$; at $7 \mu \mathrm{m}: F_{(3,20)}=34.58, p<0.0001$; at $8 \mu \mathrm{m}: F_{(3,20)}=32.81, p<0.0001$; at $\left.9 \mu \mathrm{m}: F_{(3,20)}=62.47, p<0.0001\right)$. G, Percentage of innervated cells (one-way ANOVA, $\left.F_{(3,20)}=61.99, p<0.0001\right)$ of the four experimental groups. * indicate $p<0.05 . \mathrm{N}=6 \mathrm{PV}$ cells for all experimental groups.

Nkx2.1_Cre;p75NTR ${ }^{\text {lox/lox }}$, we observed a significant increase in both the number of PV cells that were encircled by PNN, as revealed by WFA staining (Fig. 9E-G), and PNN immunofluorescence intensity around single PV cell somata (Fig. 9H). Overall, these data suggest that p75NTR expression level restrains PV cell maturation in vivo.
p75NTR activation destabilizes PV cell connectivity in adult brain

Our expression studies show that p75NTR is still expressed, albeit at a low level, in cortical PV cells in adult mice (Fig. $1 C, E, F$ ). We thus wondered whether activation of p75NTR might destabilize PV cell connectivity after it had reached maturity (around the 


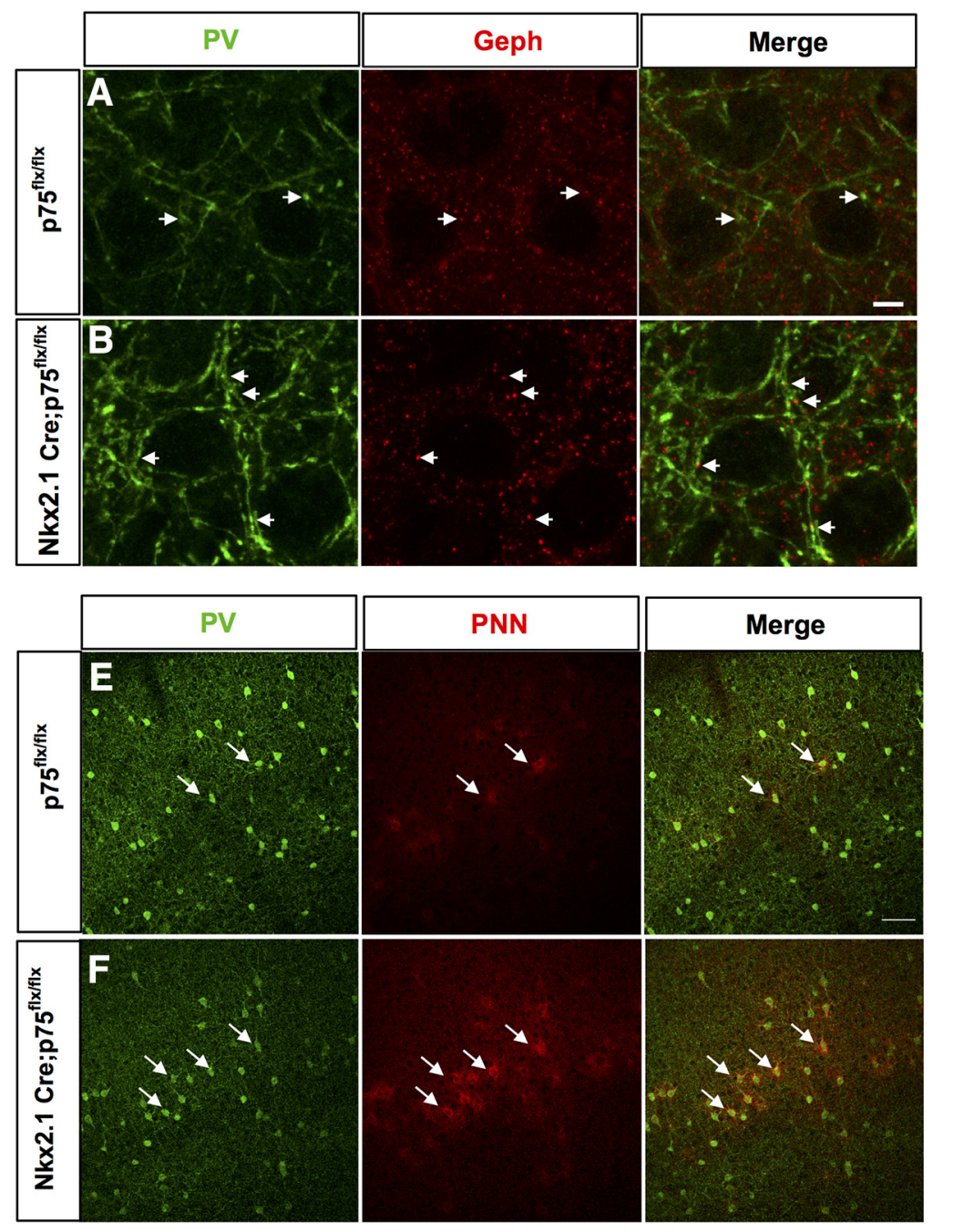

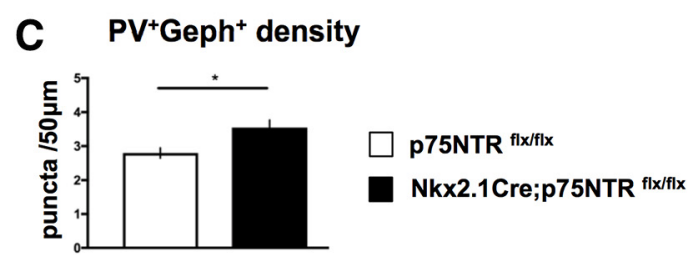

D $\mathbf{P V}^{+} \mathrm{Geph}^{+} / \mathrm{PV}^{+}$

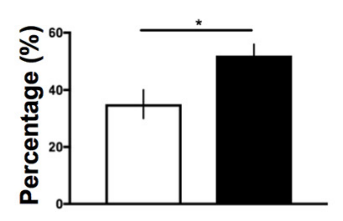

G $\quad \mathrm{PV}^{+} \mathrm{PNN}^{+} / \mathrm{PV}^{+}$

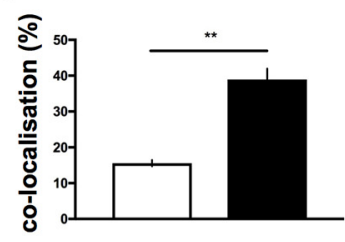

H PNN intensity

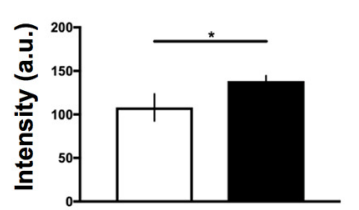

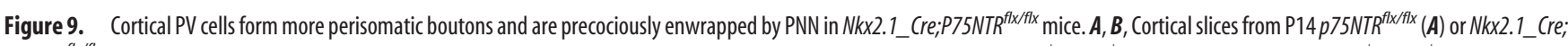

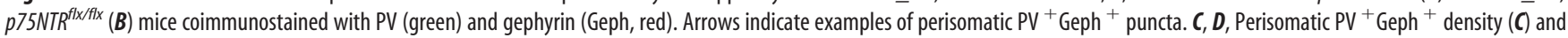
percentage of $\mathrm{PV}^{+}$puncta colabeled with gephyrin $(\boldsymbol{D})$ are significantly increased in $N k \times 2.1$ C Cre;p $75 N \mathrm{NR}^{f f \times f f x}$ mice compared with control littermates. $C$, Unpaired $t$ test, df $=8, t=2.438,{ }^{*} p=$

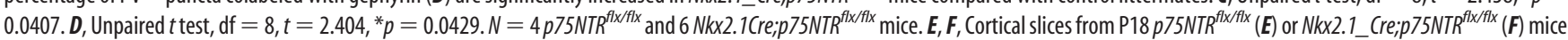
labeled with anti-PV antibody (green) and WFA, which stains perineuronal nets (PNN, red). Arrows indicate examples of PV ${ }^{+}$somata enwrapped by PNN. $\boldsymbol{G}, \boldsymbol{H}$, The proportion of PV somata surrounded by PNN (G) and mean PNN intensity $(\boldsymbol{H})$ are significantly increased in Nkx2.1_Cre;p75NTR ${ }^{f x / f l x}$ mice compared with control littermates. $\mathbf{G}$, Unpaired $t$ test, df $=4, t=7.369,{ }^{* *} p=$ 0.0018. $\boldsymbol{H}$, Unpaired $t$ test, $\mathrm{df}=4, t=3.157,{ }^{*} p=0.0343 . \mathrm{N}=3$ mice for both genotypes.

fourth postnatal week, both in cortical organotypic cultures and in vivo) (Chattopadhyaya et al., 2004). In cortical organotypic cultures, PV cells treated with mut-proBDNF from EP26-EP32, after PV cell innervations have plateaued, show a dramatic loss in both synaptic contacts and complexity of perisomatic innervation compared with age-matched, control PV cells (Fig. $10 A, C, D-F)$, whereas treatment with wt-proBDNF did not affect any of the analyzed parameters (Fig. $10 B, D-F$ ). Next, we asked whether treatment with mut-proBDNF could destabilize PV cell innervation in the adult brain in vivo. To address this question, we implanted osmotic minipumps releasing either mut-proBDNF (1 $\mu \mathrm{g} / \mathrm{ml}$, flow rate $0.5 \mu \mathrm{l} / \mathrm{h}$ ) or vehicle solution in primary visual cortex in adult mice for $5 \mathrm{~d}$ (Fig. 11A). We found that, in the cortices infused with mut-proBDNF (ipsilateral to the minipump), the intensity of perisomatic puncta immune-positive for the vesicular GABA transporter (vGAT, which labels presynaptic GABAergic terminals; data not shown) or for PV (Fig. 11B) was reduced compared with those in the vehicle-infused cortices (contralateral to the minipump) (Fig. $11 B, D$; and data not shown; $\sim 40 \%$ reduction for both $\mathrm{PV}^{+}$and
vGAT $^{+}$puncta/pyramidal soma in ipsilateral compared with contralateral cortex).

Next, we asked whether mut-proBDNF acts via p75NTR activation in adult cortical PV cells, by using PV_Cre mice to specifically remove p75NTR in PV cells well after the maturation of their connectivity (Chattopadhyaya et al., 2004). By introducing the $\mathrm{RCE}^{\mathrm{EGFP}}$ allele to drive EGFP expression in the presence of Cre, we showed that $\sim 90 \%$ of PV cells coexpressed GFP (92 \pm $1 \% ; n=4$ mice), whereas virtually all $\mathrm{GFP}^{+}$cells expressed $\mathrm{PV}$ in the adult $(>\mathrm{P} 60)$ visual cortex of PV_Cre;p75NTR ${ }^{\text {lox } / l o x}$ mice. As expected, PV_Cre;p75NTR ${ }^{l o x / l o x}$ adult mice did not show any significant difference in the number and intensity of $\mathrm{PV}^{+}$puncta formed around targeted cells compared with their control littermates $\left(p 75 N T R^{C t r l}\right)$ (perisomatic PV ring intensity: $84 \pm 6$ and $67 \pm 9$ a.u.; number of perisomatic $\mathrm{PV}^{+}$puncta: $7.9 \pm 0.9$ vs $9.2 \pm 0.2$ for $p 75 N T R^{\text {Ctrl }}$ vs PV_Cre;p75NTR ${ }^{\text {lox } / \text { lox }}$ mice, respectively; unpaired $t$ test, $p>0.1 ; n=6 P V \_C r e ; p 75 N T R^{\text {lox/lox }}$ and $n=4$ p75NTR ${ }^{C t r l}$ mice). In addition, visual cortex functional properties, analyzed by optical imaging, were not altered in adult 

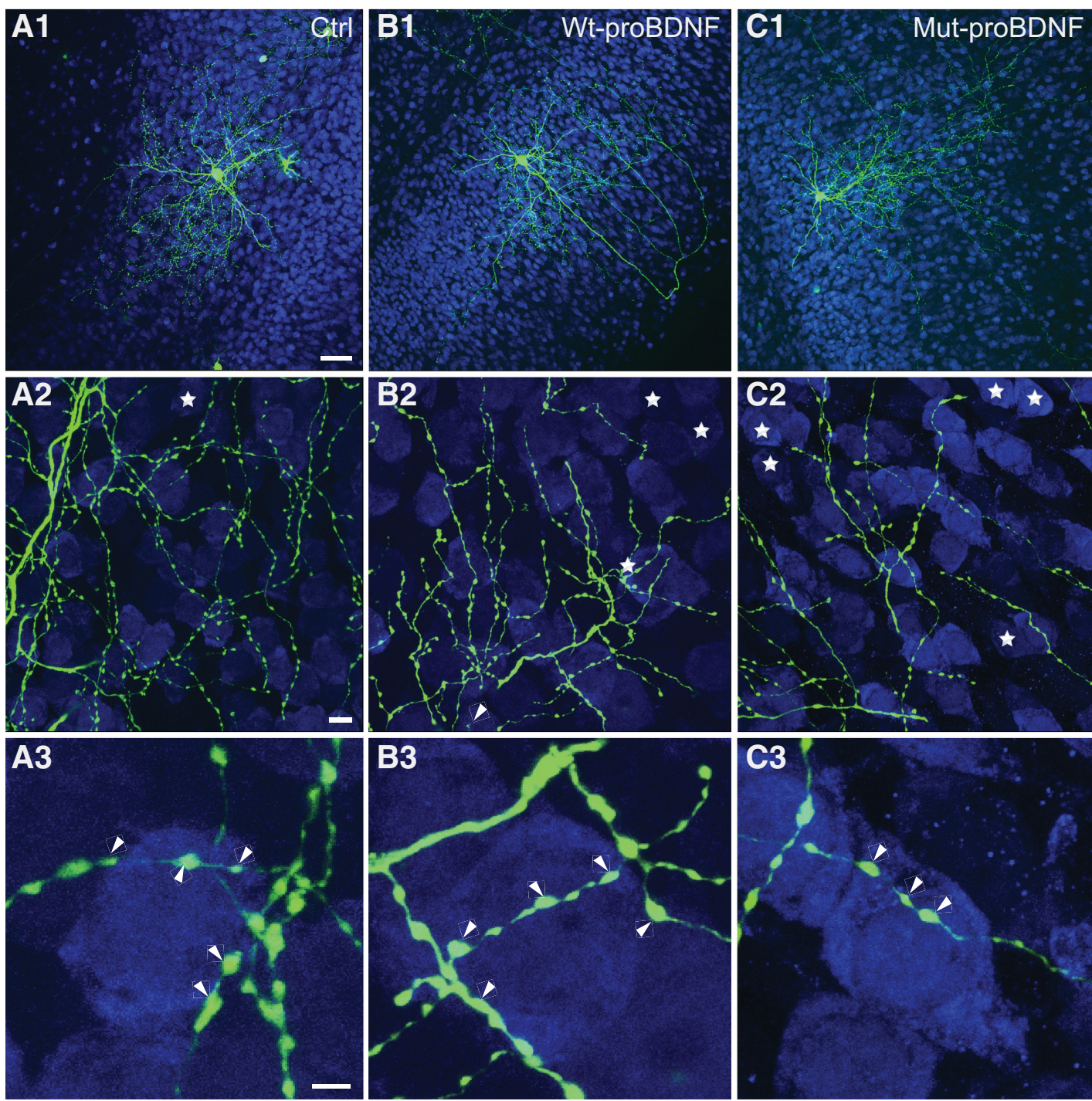

\section{Bouton density}

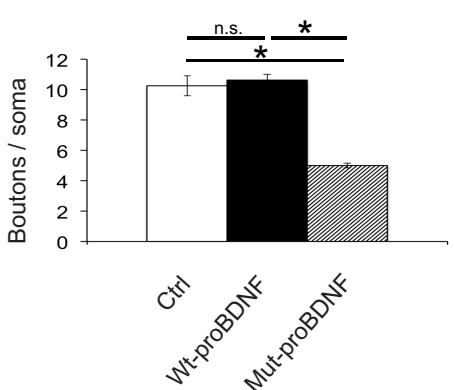

\section{E Terminal branching}

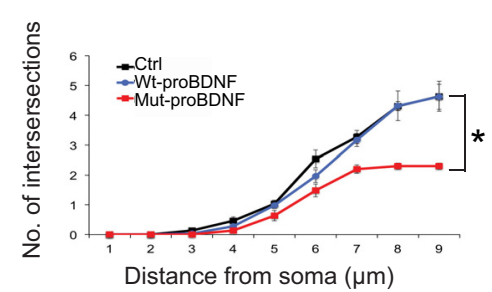

\section{F \% innervated somata}

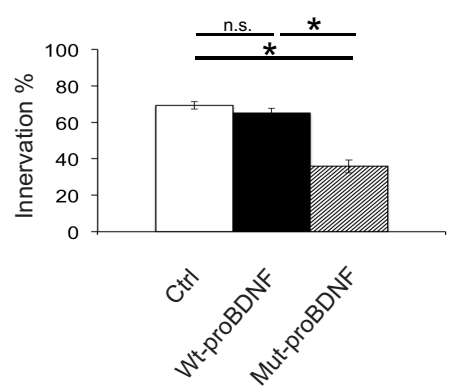

Figure 10. mut-proBDNF destabilizes PV cell innervation, even after it has reached maturity. $\boldsymbol{A}$, Control PV cell ( $\boldsymbol{A}$ 1, Ctrl, green) at EP32 with exuberant innervation field characterized by extensive branching contacting the majority of potential targets, dense boutons along axons (A2), and terminal branches with prominent and clustered boutons (A3; arrowheads) around NeuN-positive somata (blue). $\boldsymbol{B}$, PV cell treated with wt-proBDNF from EP26-EP32 shows overall similar axon size (B1), percentage of potentially targeted neurons (B2), and perisomatic innervations (B3) as control, untreated PV cells. C, PV cell treated with mut-proBDNF from EP26-EP32 shows a drastic reduction both in percentage of innervated cells (C2) and perisomatic innervation (C3). Stars indicate NeuN-positive somata that are not innervated. Scale bars:A1-C1,50 $\mu \mathrm{m} ; \boldsymbol{A 2}-\mathbf{C 2}, 10 \mu \mathrm{m} ; \boldsymbol{A 3}-\mathbf{C 3}, 5 \mu \mathrm{m} . \boldsymbol{D}$, Perisomatic bouton density (one-way ANOVA, $\left.\boldsymbol{F}_{(2,18)}=93.34, p<0.0001\right) . \boldsymbol{E}$, Terminal branching (one-way ANOVA, at $5 \mu \mathrm{m}: F_{(2,18)}=5.994, p=0.0101 ;$ at $6 \mu \mathrm{m}: F_{(2,18)}=4.790, p=0.0215 ;$ at $7 \mu \mathrm{m}: F_{(2,18)}=7.444, p=0.0044 ;$ at $8 \mu \mathrm{m}: F_{(2,18)}=14.77, p=0.0002 ;$ at $9 \mu \mathrm{m}$ : $\left.F_{(2,18)}=24.12, p<0.0001\right)$ and $(\boldsymbol{F})$ percentage of innervated cells of the three experimental groups (one-way ANOVA, $\left.F_{(2,18)}=44.29, p<0.0001\right)$. ${ }^{*}$ indicate $p<0.05 . n=9$ (trl, $n=6$ wt-proBDNF-treated PV cells, $n=6$ mut-proBDNF-treated PV cells.

PV_Cre;p75NTR ${ }^{l o x / l o x}$ mice compared with WT littermates (data not shown). Cre expression occurs slowly and starts well after P10 in this mouse line (Hippenmeyer et al., 2005); thus, p75NTR KO likely occurs too late to influence the development of basic visual abilities, such as visual acuity or contrast sensitivity (Kang et al., 2013; Picard et al., 2014).

In contrast to what we observed following mut-proBDNF infusion in control mice, mut-proBDNF infusion in mutant, 
A Saline / Mut-proBDNF
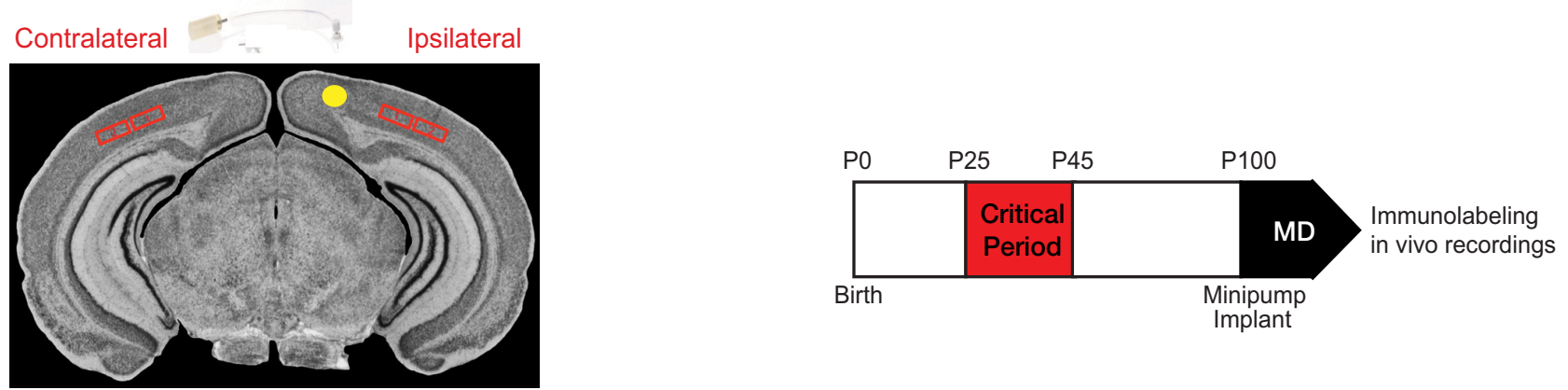

B

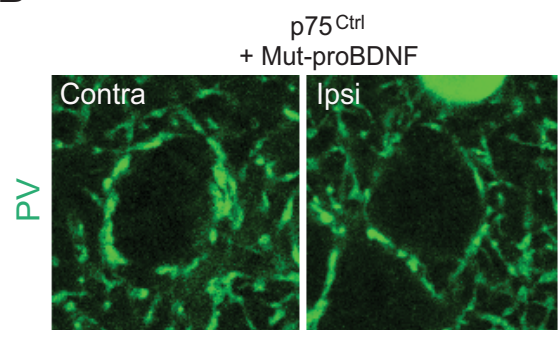

C2

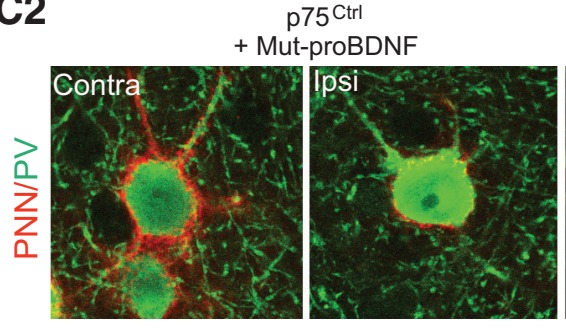

-proBDNF
PV-CRE;p75flx/flx
+ Mut-proBDNF

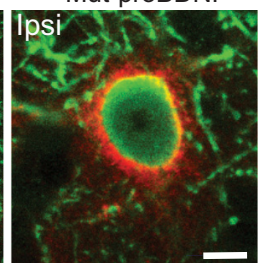

PV-CRE;p75flx/flx + Mut-proBDNF

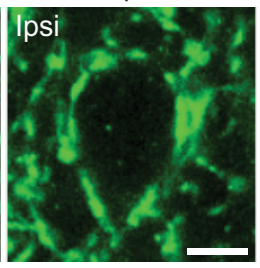

C1

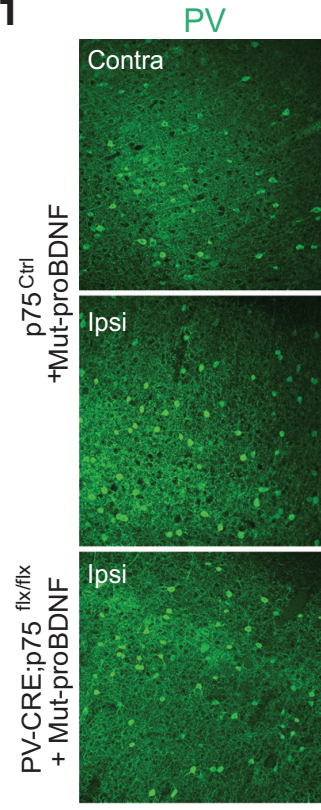

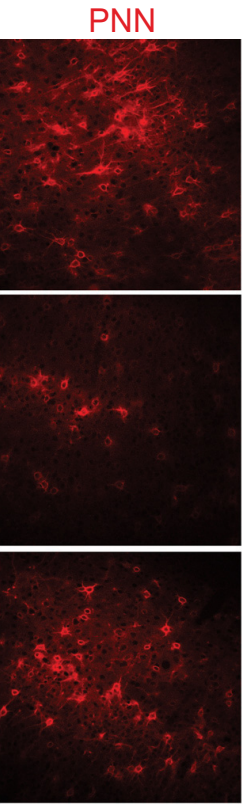

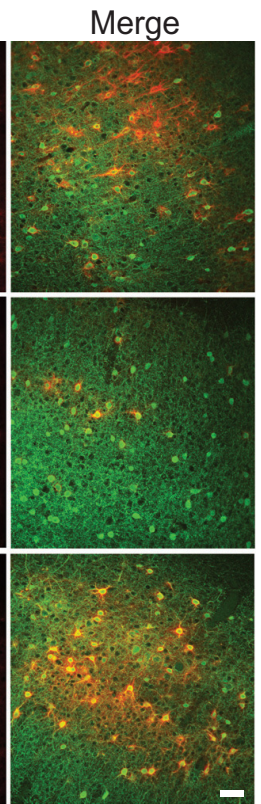

D

PV+ perisomatic puncta

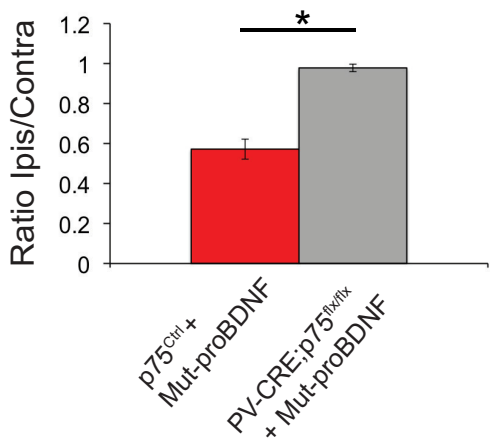

$E$

PNN intensity

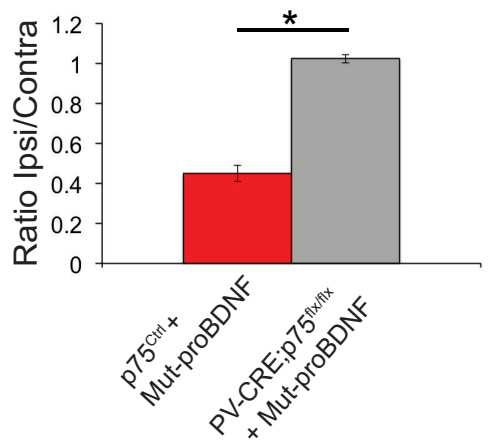

\section{F PV/PNN Co-localization}

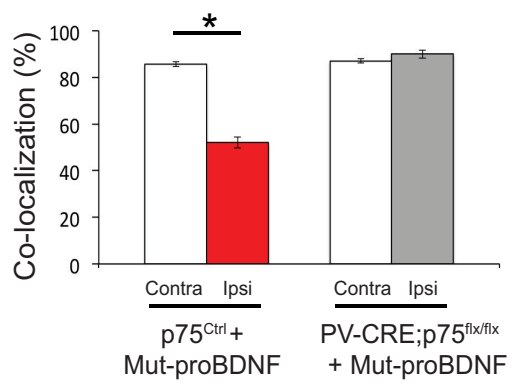

Figure 11. proBNDF-mediated p75NTR activation in cortical PV cells reduces their perisomatic boutons. $\boldsymbol{A}$, Experimental approach. $\boldsymbol{B}$, The intensity of perisomatic PV immunostaining (green) is reduced in the binocular visual cortex ipsilateral to the minipump-releasing mut-proBDNF (Ipsi) compared with the contralateral cortex (Contra) in the same animal. On the other hand, perisomatic PV intensity in the ipsilateral cortex of PV_Cre;p75 $5^{f x / f f x}$ mice is similar to that observed in the contralateral, untreated cortex. C, Low (C1) and high (C2) magnification of PNN (red, WFA staining) enwrapping PV cells (green) shows a dramatic reduction in both PNN density and intensity in the visual cortex infused with mut-proBFNF. This effect is abolished in PV_Cre;p75 $5^{f x / f l x}$ mice. Scale bars: $\mathbf{C} 1,100 \mu \mathrm{m} ; \boldsymbol{B}, \mathbf{C}, 10 \mu \mathrm{m}$. D, Quantification of the mean intensity of perisomatic PV-positive puncta in ipsilateral compared with contralateral cortex. $\mathrm{I} / \mathrm{C}$ ratio is obtained for each animal and then averaged between different animals. Mean $\mathrm{I} / \mathrm{C}$ ratio is significantly reduced in Mut-proBDNF-infused $p 75^{(t r l}$ mice compared with Mut-proBDNF-infused $P V \_C r e ; p 75^{f f x / f l x}$ mice (unpaired $t$ test, df $=$

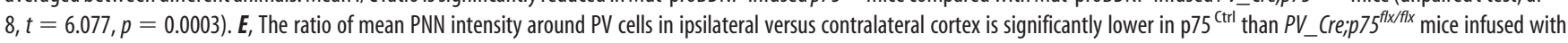
mut-proBDNF (unpaired $t$ test, $\mathrm{df}=8, t=15.33, p<0.001)$. $\boldsymbol{F}$, The percentage of PV cells colocalizing with PNN is significantly reduced in the cortex infused with mut-proBDNF (Ipsi) compared

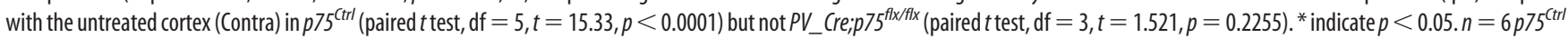
mice; $n=4 P V \_C r e ; p 75^{f l x f f x}$ mice. 
PV_Cre;p75NTR ${ }^{l o x / l o x}$ mice was unable to significantly alter perisomatic $\mathrm{PV}^{+}$(Fig. $11 \mathrm{~B}, D$ ) and $\mathrm{vGAT}^{+}$puncta intensity (data not shown), indicating that the effect of mut-proBDNF on perisomatic GABAergic boutons in adult mice was mediated by p75NTR expressed by PV cells. Together, these data suggest that activation of p75NTR onto PV cells, mediated by pharmacological proBDNF treatment, is able to destabilize PV cells connectivity in the adult brain.

\section{proBDNF-mediated $\mathrm{p} 75 \mathrm{NTR}$ activation in PV cells promotes cortical plasticity in adult mice}

Using ocular dominance plasticity in visual cortex as experimental model, recent studies showed that modulation of inhibition in adult brain can reactivate juvenile-like cortical plasticity mechanisms (Harauzov et al., 2010). Because our data showed that treatment with mut-proBDNF could destabilize PV cell innervation in the adult brain in vivo, we asked whether this could in turn promote cortical plasticity. To answer this question, we first analyzed PNN expression pattern in visual cortex of mice infused with mut-proBDNF (Fig. 11A) because it has been shown that PNNs normally enwrap mature PV cells to limit adult plasticity (Pizzorusso et al., 2002; Morishita et al., 2015). In p75NTR ${ }^{C r r l}$ mice, mut-proBDNF infusion significantly reduced both the number of PV cells that were encircled by PNN, as revealed by WFA staining (Fig. 11C1,F), and PNN immunofluorescence intensity around single $\mathrm{PV}^{+}$cells (Fig. 11C2,E; $\sim 55 \%$ reduction in ipsilateral vs contralateral cortex). The effects of mut-proBDNF treatment on PNN were completely abolished in PV_Cre; p75NTR ${ }^{l o x / l o x}$ mice (Fig. 11C1,C2,E, F). Importantly, PNN staining in visual cortex did not differ between untreated $P V \_C r e$; p75NTR ${ }^{l o x / l o x}$ mice and control littermates (PNN intensity; $143 \pm$ 6 and $148 \pm 5$ a.u.; percentage of PV cells encircled by PNN: $87.6 \pm 1.0 \%$ and $87.1 \pm 0.9 \%$, for p75NTR ${ }^{\text {Ctrl }}$ and PV_Cre; $p 75 N_{T R}{ }^{l o x / l o x}$, respectively; unpaired $t$ test, $p>0.1, n=6$ PV_Cre;p75NTR ${ }^{\text {lox/lox }}$ and $n=4$ p75NTR ${ }^{C t r l}$ mice), suggesting that p75NTR activation by mut-proBDNF treatment was the critical step leading to PNN reduction.

To directly test whether mut-proBDNF could reopen a window of plasticity in adult visual cortex, we performed electrophysiological recordings in the binocular region of the primary visual cortex following a brief $(3 \mathrm{~d})$ monocular deprivation in adult mice. During the critical period for ocular dominance plasticity, the ratio of the amplitudes of VEPs evoked by eye stimulation shifts in favor of the nondeprived eye (ocular dominance shift). However, no significant ocular dominance shift can be observed following $3 \mathrm{~d}$ of monocular deprivation at or after P100 (Pizzorusso et al., 2002; Lehmann and Löwel, 2008). Consistently, we found that monocular deprivation did not affect the C/I VEP ratio in vehicle-treated animals with respect to p75NTR ${ }^{C t r l}$ nondeprived mice, whereas in $p 75 N T R^{C t r l}$ mice treated with mut-proBDNF, we observed a marked ocular dominance shift in favor of the nondeprived eye, reflected by a significant decrease of the C/I VEP ratio (Fig. 12A,B). p75NTR deletion in PV cells (PV_Cre;p75NTR $\left.{ }^{\text {lox/lox }}\right)$ completely prevented the ocular dominance shift induced by mut-proBDNF treatment (Fig. 12A,B).

To further confirm these data, we performed single-unit recordings. Ocular dominance of cortical neurons was assessed by quantitative evaluation of responsiveness to optimal visual stimulation of either eye, and an ODI was assigned to every single cell recorded. ODI of vehicle-infused, monocularly deprived, p $75 N R^{C t r l}$ mice displayed the typical bias toward the contralateral eye inputs as shown by nondeprived control mice, whereas
mut-proBDNF infused, monocularly deprived, $p 75 N T R^{C t r l}$ mice showed a prominent ocular dominance shift in favor of the open eye (Fig. 12C), which was abolished in PV_Cre;p75NTR Rox/lox $^{\text {lo }}$ mice (Fig. 12C), further proving that mut-proBDNF treatment was able to induce visual experience-dependent plasticity only in mice carrying intact p75NTR expression in PV cells. The absence

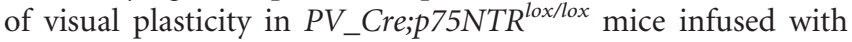
mut-proBDNF could be due to developmental confounding effects, but we think this is unlikely because we did not find significant differences in PV cell perisomatic connectivity, PNN intensity, and visual cortical properties in the visual cortex of adult PV_Cre;p75NTR ${ }^{l o x / l o x}$ mice compared with their control littermates. Interestingly, we found that spontaneous discharge of visual cortical neurons was increased by mut-proBDNF treatment only in $p 75 N T R^{C t r l}$ mice (Fig. $12 D$ ), which could be partly due to reduced cortical inhibition following proBDNF-mediated p75NTR activation in PV cells.

In summary, these data demonstrate that p75NTR activation in cortical PV cells induces loss of PV cell connectivity and restoration of ocular dominance plasticity in adult mice.

\section{Discussion}

In this study, we focused on the role of p75NTR in regulating interneuron synapse maturation during development and adult visual cortical plasticity. We had to first overcome the technical challenge of visualizing the presence of p75NTR in PV interneurons during development and in the adult cortex. Using two cutting-edge experimental approaches to detect very low levels of RNA and protein, we were able to confirm that PV cells express the mRNA for p75NTR and to specifically detect p75NTR in not just PV cell somata but also in presynaptic terminals. Next, we showed that p75NTR expression levels and activation modulate the formation of PV cell connectivity during development in organotypic cultures and in vivo. Finally, we proved that pharmacological activation of p75NTR in PV cells reduces PV cell connectivity and allows juvenile-like plasticity, in adult visual cortex.

During development, p75NTR is downregulated after the third postnatal week, while at the same time PV cells develop complex, highly branched axonal arbors that contact an increasingly higher number of potential postsynaptic targets (Chattopadhyaya et al., 2004). Our results show that PV cell-specific p75NTR gene loss accelerates, whereas p75NTR activation hinders the development of complex perisomatic innervation fields. In particular, the innervation-promoting effects of p75NTR deletion in single, sparse PV cells in otherwise WT organotypic cultures suggest that p75NTR acts in a cell-autonomous fashion to regulate PV cell innervation fields. Consistent with the results observed in vitro, early deletion of p75NTR in PV cells in vivo accelerates the development of PV cell perisomatic synapses and of PNN aggregation around PV cell somata, which is an indication of the maturation state of PV cells. Thus, p75NTR acts as a negative signal constraining the formation of PV cell connectivity. The polysialic acid motif PSA was previously shown to hinder PV cell synapse formation before eye opening (Di Cristo et al., 2007). PSA is a general modulator of cell interactions; and as such, it likely acts as a permissive signal to allow optimal interactions between presynaptic PV axons and postsynaptic cells. On the other hand, here, our data show that p75NTR expression levels specifically in PV cells negatively regulates the extent of its innervations field. Therefore, it is possible that p75NTR expression level may act as an instructive signal for PV cell innervation refinement. Indeed, using PLA, we found that a population of PV cell boutons colocalizes with p75NTR. Locally, p75NTR activa- 
A $\quad \mathrm{p} 75^{\mathrm{Ctrl}}+$ vehicle
$\mathrm{p} 75^{\mathrm{Ctrl}}+$
Mut-proBDNF
PV-CRE;p75 flxfflx
+ Mut-proBDNF

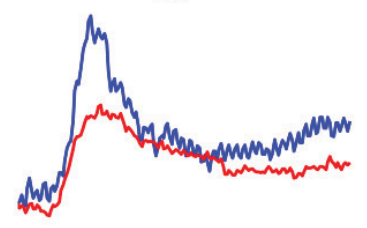

Mntmans

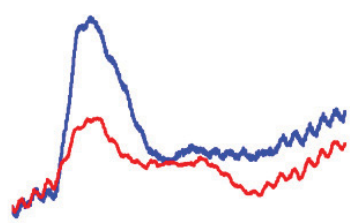

B

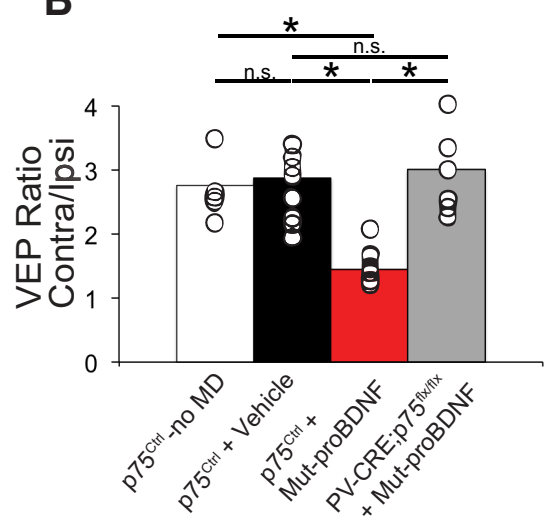

C

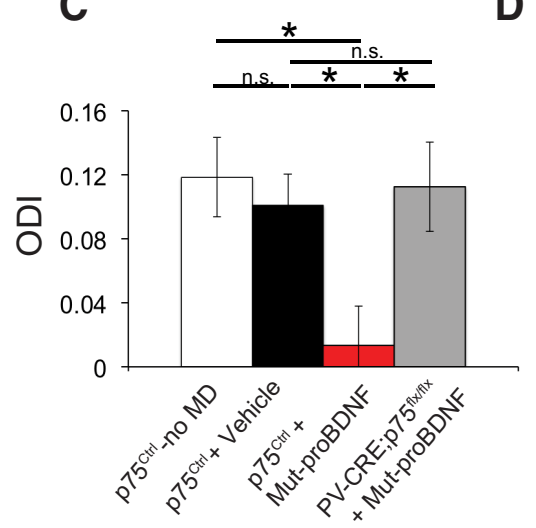

D

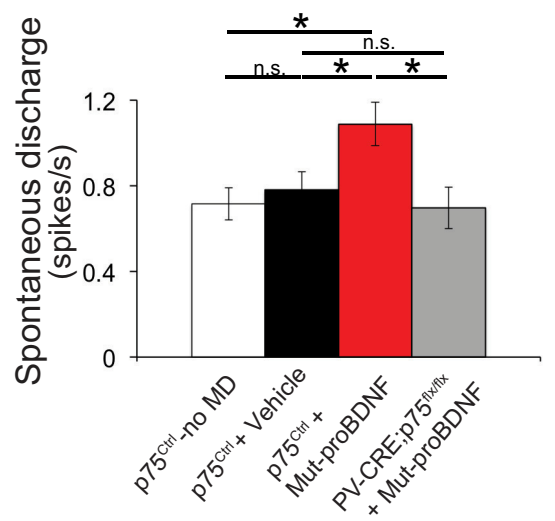

Figure 12. proBNDF-mediated p75NTR activation in cortical PV cells restores ocular dominance plasticity in adult visual cortex in vivo. $\boldsymbol{A}$, Typical VEP responses to the stimulation of either contralateral (blue) or ipsilateral (red) eye to the cortex in which the recording is performed in $p 75 N T R^{C t r l}$ mice infused with either vehicle or mut-proBDNF, and PV_Cre;p75NTR ${ }^{f x} f f l x$ mice infused with mut-proBDNF. Calibration bars: $50 \mu \mathrm{V}, 100 \mathrm{~ms}$. B, C/I VEP ratio mean values. Three days of monocular deprivation do not affect the C/I VEP ratio in adult mice, although it leads to a significant decrease in the C/IVEP ratio in animals treated with mut-proBDNF. Mut-proBDNF effects are, however, abolished in PV_Cre;p75 $5^{f f f f l}$ mice (one-way ANOVA, $\left.F_{(2,18)}=8.903, p=0.0021\right) . p 75 N T R^{C t r l}$

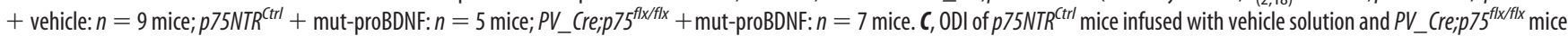
infused with mut-proBDNF are not significantly different from those of undeprived animals, whereas $0 D I s$ in $p 75^{c t r l}$ mice treated with mut-proBDNF are significantly shifted toward the open eye (one-way ANOVA, $\left.F_{(2,443)}=5.203, p=0.0058\right)$. D. Mean spontaneous discharge is significantly increased only in $p 75^{\mathrm{ctrl}}$ mice treated with mut-proBDNF (one-way ANOVA, $F_{(2,443)}=4.580, p=$ 0.0107). p75NTR ${ }^{\text {ctrl }}+$ vehicle: $n=9$ mice, 174 cells; $p 75$ TTR $^{\text {ctrl }}+$ mut-proBDNF: $n=5$ mice, 147 cells; PV_Cre;p75 $5^{f x / f f x}+$ mut-proBDNF: $n=6$ mice, 125 cells. Gray area represents the C/I VEP ratio $(\boldsymbol{B})$ or the $\mathrm{ODI}$ range $(\boldsymbol{C})$ (mean \pm SEM) in adult nondeprived animals $(n=5$ mice, 99 cells). * indicate $p<0.05$.

tion may inhibit the formation of PV cell innervation by promoting growth cone collapse, via activation of RhoA (Naska et al., 2010; Sun et al., 2012) and/or inactivation of Rac signaling, which leads to destabilization of actin filaments and collapse of neurite outgrowth (Deinhardt et al., 2011). Further, p75NTR activation may sensitizes neurons to other inhibitory, growth cone collapsing cues, such as Nogo (Yamashita and Tohyama, 2003; Yamashita et al., 2005), ephrins and semaphorins (Lim et al., 2008; Naska et al., 2010). It will be interesting to study whether and how these inhibitory cues interact with p75NTR signaling to modulate the maturation of PV cell innervation. In addition to locally regulating cytoskeletal dynamics, p75NTR activation may cause changes in gene transcription, leading to modulation in expression of proteins modifying PV cell synaptic inputs and/or excitability, which would in turn regulate PV cell axon growth (Baho and Di Cristo, 2012).

There are open questions regarding mechanisms regulating p75NTR downregulation during development. One study suggests that $\mathrm{p} 75 \mathrm{NTR}$ mRNA is negatively regulated by visual experience in vivo (Bracken and Turrigiano, 2009). It is conceivable that activity levels in individual PV cells regulate their p75NTR expression, which in turn determines to what extent they respond to local changes in molecular p75NTR regulators. In addition, p75NTR expression is regulated by early growth response (Egr) factors 1 and 3, which are inducible transcriptional regulators modulating gene expression in response to a variety of extracellular stimuli influencing cellular growth, differentiation, and response to injury (Gao et al., 2007), suggesting a potentially highly dynamic, and cell context-dependent mechanism for regulation of p75NTR expression during development or following injury. Accordingly, it has been shown that p75NTR is upregulated by pathological events, including cerebral ischemia (Irmady et al., 2014) and seizures (Unsain et al., 2008; Volosin et al., 2008). One implication of our findings is that pathology-induced upregulation of p75NTR levels occurring during early brain development impairs the maturation of PV cell circuits, which may in turn affect the expression and/or timing of critical period plasticity (Di Cristo et al., 2007; Sugiyama et al., 2008), thus contributing to long-term cognitive and behavioral impairments.

In adults, the brain's intrinsic potential for plasticity is actively dampened by the increase in intracortical inhibition and the simultaneous expression of brake-like factors, which limit experience-dependent circuit rewiring beyond a critical period. Interestingly, many of these plasticity breaks converge onto PV cell function (Pizzorusso et al., 2002; Bavelier et al., 2010; Beurdeley et al., 2012). Our results demonstrate that reducing PV cell connectivity by inducing p75NTR activation is sufficient to reinstate ocular dominance plasticity in the adult cortex. p75NTR activation may directly affect the stability of PV cell axonal branches and synapses by affecting local cytoskeletal dynamics 
(Deinhardt et al., 2011; Sun et al., 2012) or/and affect the synthesis of specific proteins, including those required for PNN condensation around PV-positive cells (Carulli et al., 2010). Intact PNNs structurally limit synaptic rearrangements of inputs onto PV cells, which in turn regulate their excitability and synaptic release. Consistently, reduction of PV cell excitability leads to a reduction of their innervation fields, even after reaching maturity (Baho and Di Cristo, 2012). Further, PNN disruption may prevent the persistent uptake of the homeoprotein Otx2 into PV cells, which is required by the PV cells for the maintenance of an adult phenotype (Sugiyama et al., 2008; Beurdeley et al., 2012).

Although our data show that PV cell perisomatic synapse formation and PNN colocalization were significantly accelerated in the visual cortex of Nkx2.1_Cre;p75NTR ${ }^{l o x / l o x}$ mice in which Cre expression starts during early development, we did not find significant differences in either PV cell perisomatic connectivity or basic visual properties in adult $P V_{-} C r e ; p 75 N T R^{l o x / l o x}$ mice. One likely explanation is that, in these latter mice, the removal of p75NTR protein occurs too late to affect the maturation of these parameters in the visual cortex, which have for the most part reached plateau by the first postnatal month (Chattopadhyaya et al., 2004; Kang et al., 2013; Picard et al., 2014). Because p75NTR expression differs among brain regions at the different ages (Holm et al., 2009; Giza et al., 2018), it would be interesting to investigate whether PV_Cre; $75 N_{T} R^{\text {lox/lox }}$ conditional KO mice show altered cognitive functions implicating regions which mature later, such as the PFC (Giza et al., 2018).

The role of neurotrophins and their precursor forms in p75NTR-mediated signaling has been the subject of several debates. Numerous studies have shown that proNGF and proBDNF can promote cell death by interacting with a receptor complex consisting of p75NTR and sortilin (Nykjaer et al., 2004; Teng et al., 2005) and that the extracellular conversion from proBDNF into BDNF promotes LTD in the hippocampus, by activating p75NTR (Pang et al., 2004; Woo et al., 2005). In addition, while it was well accepted that the prodomain plays a role in the folding, stability, and intracellular trafficking of BDNF (Kolbeck et al., 1994), recent data suggest that the prodomain per se may have diverse biological functions. First, Dieni et al. (2012) reported that BDNF and its propeptide both stained large dense core vesicles in excitatory presynaptic terminals of the adult mouse hippocampus. Second, Mizui et al. (2015) showed that the BDNF propeptide facilitates LTD in the hippocampus. Third, Anastasia et al. (2013) showed that the prodomain is detected at high levels in the hippocampus in vivo, in particular after the first postnatal month, and that its secretion is activity-dependent in hippocampal neuronal cultures. Based on the relative expression of proBDNF, mBDNF, and pBDNF during development and in the adult brain (Yang et al., 2009; Rauskolb et al., 2010; Dieni et al., 2012; Anastasia et al., 2013), it has been hypothesized that secreted proBDNF may play a role during early development, whereas the secreted prodomain may have biological effects in the adolescent and adult brain (Zanin et al., 2017). Consistently, our data show that modulating endogenous mBDNF levels by acting on tPA activity before the third postnatal week affects the development of PV cell innervation and that this depends on p75NTR expression by PV cells.

A common single nucleotide polymorphism in the human $B D N F$ gene results in a Val66Met substitution in the pBDNF region, which is associated with impairments in specific forms of learning and memory and with enhanced risk of developing depression and anxiety disorders in humans and mice (Chen et al., 2006; Soliman et al., 2010; Zhang et al., 2014). Because at least a subset of PV cells express p75NTR, even in adulthood, it will be interesting to investigate whether the presence of the Met66 variant alters the formation and/or plasticity of PV cell innervation, thereby contributing to the endophenotypes related to neuropsychiatric disorders associated with the Val66Met polymorphism in humans.

\section{References}

Anastasia A, Deinhardt K, Chao MV, Will NE, Irmady K, Lee FS, Hempstead BL, Bracken C (2013) Val66Met polymorphism of BDNF alters prodomain structure to induce neuronal growth cone retraction. Nat Commun 4:2490.

Baho E, Di Cristo G (2012) Neural activity and neurotransmission regulate the maturation of the innervation field of cortical GABAergic interneurons in an age-dependent manner. J Neurosci 32:911-918.

Bavelier D, Levi DM, Li RW, Dan Y, Hensch TK (2010) Removing brakes on adult brain plasticity: from molecular to behavioral interventions. J Neurosci 30:14964-14971.

Beurdeley M, Spatazza J, Lee HH, Sugiyama S, Bernard C, Di Nardo AA, Hensch TK, Prochiantz A (2012) Otx2 binding to perineuronal nets persistently regulates plasticity in the mature visual cortex. J Neurosci 32:9429-9437.

Bogenmann E, Thomas PS, Li Q, Kim J, Yang LT, Pierchala B, Kaartinen V (2011) Generation of mice with a conditional allele for the p75(NTR) neurotrophin receptor gene. Genesis 49:862-869.

Bolte S, Cordelières FP (2006) A guided tour into subcellular colocalization analysis in light microscopy. J Microsc 224:213-232.

Bracken BK, Turrigiano GG (2009) Experience-dependent regulation of TrkB isoforms in rodent visual cortex. Dev Neurobiol 69:267-278.

Cardin JA, Carlén M, Meletis K, Knoblich U, Zhang F, Deisseroth K, Tsai LH, Moore CI (2009) Driving fast-spiking cells induces gamma rhythm and controls sensory responses. Nature 459:663-667.

Carulli D, Pizzorusso T, Kwok JC, Putignano E, Poli A, Forostyak S, Andrews MR, Deepa SS, Glant TT, Fawcett JW (2010) Animals lacking link protein have attenuated perineuronal nets and persistent plasticity. Brain 133:2331-2347.

Charalampopoulos I, Vicario A, Pediaditakis I, Gravanis A, Simi A, Ibáñez CF (2012) Genetic dissection of neurotrophin signaling through the p75 neurotrophin receptor. Cell Rep 2:1563-1570.

Chattopadhyaya B, Di Cristo G, Higashiyama H, Knott GW, Kuhlman SJ, Welker E, Huang ZJ (2004) Experience and activity-dependent maturation of perisomatic GABAergic innervation in primary visual cortex during a postnatal critical period. J Neurosci 24:9598-9611.

Chattopadhyaya B, Di Cristo G, Wu CZ, Knott G, Kuhlman S, Fu Y, Palmiter RD, Huang ZJ (2007) GAD67-mediated GABA synthesis and signaling regulate inhibitory synaptic innervation in the visual cortex. Neuron 54: 889-903.

Chattopadhyaya B, Baho E, Huang ZJ, Schachner M, Di Cristo G (2013) Neural cell adhesion molecule-mediated fyn activation promotes GABAergic synapse maturation in postnatal mouse cortex. J Neurosci 33:5957-5968.

Chen ZY, Jing D, Bath KG, Ieraci A, Khan T, Siao CJ, Herrera DG, Toth M, Yang C, McEwen BS, Hempstead BL, Lee FS (2006) Genetic variant BDNF (Val66Met) polymorphism alters anxiety-related behavior. Science 314:140-143.

Cho KK, Hoch R, Lee AT, Patel T, Rubenstein JL, Sohal VS (2015) Gamma rhythms link prefrontal interneuron dysfunction with cognitive inflexibility in Dlx5/6(+/-) mice. Neuron 85:1332-1343.

Cho RY, Konecky RO, Carter CS (2006) Impairments in frontal cortical gamma synchrony and cognitive control in schizophrenia. Proc Natl Acad Sci U S A 103:19878-19883.

Deinhardt K, Kim T, Spellman DS, Mains RE, Eipper BA, Neubert TA, Chao MV, Hempstead BL (2011) Neuronal growth cone retraction relies on proneurotrophin receptor signaling through Rac. Sci Signal 4:ra82.

Del Pino I, García-Frigola C, Dehorter N, Brotons-Mas JR, Alvarez-Salvado E, Martínez de Lagrán M, Ciceri G, Gabaldón MV, Moratal D, Dierssen M, Canals S, Marín O, Rico B (2013) Erbb4 deletion from fast-spiking interneurons causes schizophrenia-like phenotypes. Neuron 79:11521168.

Di Cristo G, Chattopadhyaya B, Kuhlman SJ, Fu Y, Bélanger MC, Wu CZ, Rutishauser U, Maffei L, Huang ZJ (2007) Activity-dependent PSA ex- 
pression regulates inhibitory maturation and onset of critical period plasticity. Nat Neurosci 10:1569-1577.

Dienel SJ, Lewis DA (2018) Alterations in cortical interneurons and cognitive function in schizophrenia. Neurobiol Dis. Advance online publication. Retrieved September 26, 2018. doi:10.1016/j.nbd.2018.06.020.

Dieni S, Matsumoto T, Dekkers M, Rauskolb S, Ionescu MS, Deogracias R, Gundelfinger ED, Kojima M, Nestel S, Frotscher M, Barde YA (2012) $\mathrm{BDNF}$ and its pro-peptide are stored in presynaptic dense core vesicles in brain neurons. J Cell Biol 196:775-788.

Do KQ, Cuenod M, Hensch TK (2015) Targeting oxidative stress and aberrant critical period plasticity in the developmental trajectory to schizophrenia. Schizophr Bull 41:835-846.

Fagiolini M, Hensch TK (2000) Inhibitory threshold for critical-period activation in primary visual cortex. Nature 404:183-186.

Fagiolini M, Fritschy JM, Löw K, Möhler H, Rudolph U, Hensch TK (2004) Specific GABAA circuits for visual cortical plasticity. Science 303:16811683.

Fries P (2009) Neuronal gamma-band synchronization as a fundamental process in cortical computation. Annu Rev Neurosci 32:209-224.

Fries P, Reynolds JH, Rorie AE, Desimone R (2001) Modulation of oscillatory neuronal synchronization by selective visual attention. Science 291:1560-1563.

Gao X, Daugherty RL, Tourtellotte WG (2007) Regulation of low affinity neurotrophin receptor (p75NTR) by early growth response (Egr) transcriptional regulators. Mol Cell Neurosci 36:501-514.

Giza JI, Kim J, Meyer HC, Anastasia A, Dincheva I, Zheng CI, Lopez K, Bains H, Yang J, Bracken C, Liston C, Jing D, Hempstead BL, Lee FS (2018) The BDNF Val66Met prodomain disassembles dendritic spines altering fear extinction circuitry and behavior. Neuron 99:163-178.e6.

Groleau M, Nguyen HN, Vanni MP, Huppé-Gourgues F, Casanova C, Vaucher E (2014) Impaired functional organization in the visual cortex of muscarinic receptor knock-out mice. Neuroimage 98:233-242.

Harauzov A, Spolidoro M, DiCristo G, De Pasquale R, Cancedda L, Pizzorusso T, Viegi A, Berardi N, Maffei L (2010) Reducing intracortical inhibition in the adult visual cortex promotes ocular dominance plasticity. J Neurosci 30:361-371.

Hippenmeyer S, Vrieseling E, Sigrist M, Portmann T, Laengle C, Ladle DR, Arber S (2005) A developmental switch in the response of DRG neurons to ETS transcription factor signaling. PLoS Biol 3:e159.

Holm MM, Nieto-Gonzalez JL, Vardya I, Vaegter CB, Nykjaer A, Jensen K (2009) Mature BDNF, but not proBDNF, reduces excitability of fastspiking interneurons in mouse dentate gyrus. J Neurosci 29:12412-12418.

Hong EJ, McCord AE, Greenberg ME (2008) A biological function for the neuronal activity-dependent component of BDNF transcription in the development of cortical inhibition. Neuron 60:610-624.

Howard MW, Rizzuto DS, Caplan JB, Madsen JR, Lisman J, AschenbrennerScheibe R, Schulze-Bonhage A, Kahana MJ (2003) Gamma oscillations correlate with working memory load in humans. Cereb Cortex 13:13691374.

Huang ZJ, Kirkwood A, Pizzorusso T, Porciatti V, Morales B, Bear MF, Maffei L, Tonegawa S (1999) BDNF regulates the maturation of inhibition and the critical period of plasticity in mouse visual cortex. Cell 98:739-755.

Irmady K, Jackman KA, Padow VA, Shahani N, Martin LA, Cerchietti L, Unsicker K, Iadecola C, Hempstead BL (2014) Mir-592 regulates the induction and cell death-promoting activity of p75NTR in neuronal ischemic injury. J Neurosci 34:3419-3428.

Je HS, Yang F, Ji Y, Potluri S, Fu XQ, Luo ZG, Nagappan G, Chan JP, Hempstead B, Son YJ, Lu B (2013) ProBDNF and mature BDNF as punishment and reward signals for synapse elimination at mouse neuromuscular junctions. J Neurosci 33:9957-9962.

Kang E, Durand S, LeBlanc JJ, Hensch TK, Chen C, Fagiolini M (2013) Visual acuity development and plasticity in the absence of sensory experience. J Neurosci 33:17789-17796.

Kobayashi Y, Ye Z, Hensch TK (2015) Clock genes control cortical critical period timing. Neuron 86:264-275.

Kohara K, Yasuda H, Huang Y, Adachi N, Sohya K, Tsumoto T (2007) A local reduction in cortical GABAergic synapses after a loss of endogenous brain-derived neurotrophic factor, as revealed by single-cell gene knockout method. J Neurosci 27:7234-7244.

Kolbeck R, Jungbluth S, Barde YA (1994) Characterisation of neurotrophin dimers and monomers. Eur J Biochem 225:995-1003.
Lehmann K, Löwel S (2008) Age-dependent ocular dominance plasticity in adult mice. PLoS One 3:e3120.

Lim YS, McLaughlin T, Sung TC, Santiago A, Lee KF, O’Leary DD (2008) p75(NTR) mediates ephrin-A reverse signaling required for axon repulsion and mapping. Neuron 59:746-758.

Lin Z, Tann JY, Goh ET, Kelly C, Lim KB, Gao JF, Ibanez CF (2015) Structural basis of death domain signaling in the p75 neurotrophin receptor. eLife 4:e11692.

Mizui T, Ishikawa Y, Kumanogoh H, Lume M, Matsumoto T, Hara T, Yamawaki S, Takahashi M, Shiosaka S, Itami C, Uegaki K, Saarma M, Kojima M (2015) BDNF pro-peptide actions facilitate hippocampal LTD and are altered by the common BDNF polymorphism Val66Met. Proc Natl Acad Sci U S A 112:E3067-E3074.

Morishita H, Cabungcal JH, Chen Y, Do KQ, Hensch TK (2015) Prolonged period of cortical plasticity upon redox dysregulation in fast-spiking interneurons. Biol Psychiatry 78:396-402.

Naska S, Lin DC, Miller FD, Kaplan DR (2010) p75NTR is an obligate signaling receptor required for cues that cause sympathetic neuron growth cone collapse. Mol Cell Neurosci 45:108-120.

Nykjaer A, Lee R, Teng KK, Jansen P, Madsen P, Nielsen MS, Jacobsen C, Kliemannel M, Schwarz E, Willnow TE, Hempstead BL, Petersen CM (2004) Sortilin is essential for proNGF-induced neuronal cell death. Nature 427:843-848.

Pang PT, Teng HK, Zaitsev E, Woo NT, Sakata K, Zhen S, Teng KK, Yung WH, Hempstead BL, Lu B (2004) Cleavage of proBDNF by tPA/plasmin is essential for long-term hippocampal plasticity. Science 306:487-491.

Picard N, Leslie JH, Trowbridge SK, Subramanian J, Nedivi E, Fagiolini M (2014) Aberrant development and plasticity of excitatory visual cortical networks in the absence of cpg15. J Neurosci 34:3517-3522.

Pizzorusso T, Medini P, Berardi N, Chierzi S, Fawcett JW, Maffei L (2002) Reactivation of ocular dominance plasticity in the adult visual cortex. Science 298:1248-1251.

Porciatti V, Pizzorusso T, Maffei L (1999) The visual physiology of the wild type mouse determined with pattern VEPs. Vision Res 39:3071-3081.

Rauskolb S, Zagrebelsky M, Dreznjak A, Deogracias R, Matsumoto T, Wiese S, Erne B, Sendtner M, Schaeren-Wiemers N, Korte M, Barde YA (2010) Global deprivation of brain-derived neurotrophic factor in the CNS reveals an area-specific requirement for dendritic growth. J Neurosci 30: $1739-1749$.

Schwartz N, Schohl A, Ruthazer ES (2011) Activity-dependent transcription of BDNF enhances visual acuity during development. Neuron 70: $455-467$.

Sohal VS, Zhang F, Yizhar O, Deisseroth K (2009) Parvalbumin neurons and gamma rhythms enhance cortical circuit performance. Nature 459 : $698-702$.

Soliman F, Glatt CE, Bath KG, Levita L, Jones RM, Pattwell SS, Jing D, Tottenham N, Amso D, Somerville LH, Voss HU, Glover G, Ballon DJ, Liston C, Teslovich T, Van Kempen T, Lee FS, Casey BJ (2010) A genetic variant BDNF polymorphism alters extinction learning in both mouse and human. Science 327:863-866.

Sugiyama S, Di Nardo AA, Aizawa S, Matsuo I, Volovitch M, Prochiantz A, Hensch TK (2008) Experience-dependent transfer of Otx2 homeoprotein into the visual cortex activates postnatal plasticity. Cell 134:508-520.

Sun Y, Lim Y, Li F, Liu S, Lu JJ, Haberberger R, Zhong JH, Zhou XF (2012) ProBDNF collapses neurite outgrowth of primary neurons by activating RhoA. PloS One 7:e35883.

Takada N, Pi HJ, Sousa VH, Waters J, Fishell G, Kepecs A, Osten P (2014) A developmental cell-type switch in cortical interneurons leads to a selective defect in cortical oscillations. Nat Commun 5:5333.

Telley L, Cadilhac C, Cioni JM, Saywell V, Jahannault-Talignani C, Huettl RE, Sarrailh-Faivre C, Dayer A, Huber AB, Ango F (2016) Dual function of NRP1 in axon guidance and subcellular target recognition in cerebellum. Neuron 91:1276-1291.

Teng HK, Teng KK, Lee R, Wright S, Tevar S, Almeida RD, Kermani P, Torkin R, Chen ZY, Lee FS, Kraemer RT, Nykjaer A, Hempstead BL (2005) ProBDNF induces neuronal apoptosis via activation of a receptor complex of p75NTR and sortilin. J Neurosci 25:5455-5463.

Unsain N, Nuñez N, Anastasía A, Mascó DH (2008) Status epilepticus induces a TrkB to $\mathrm{p} 75$ neurotrophin receptor switch and increases brainderived neurotrophic factor interaction with p 75 neurotrophin receptor: an initial event in neuronal injury induction. Neuroscience 154:978-993.

Volosin M, Trotter C, Cragnolini A, Kenchappa RS, Light M, Hempstead BL, 
Carter BD, Friedman WJ (2008) Induction of proneurotrophins and activation of p75NTR-mediated apoptosis via neurotrophin receptorinteracting factor in hippocampal neurons after seizures. J Neurosci 28:9870-9879.

Wang F, Flanagan J, Su N, Wang LC, Bui S, Nielson A, Wu X, Vo HT, Ma XJ, Luo Y (2012) RNAscope: a novel in situ RNA analysis platform for formalin-fixed, paraffin-embedded tissues. J Mol Diagn 14:22-29.

Winnubst J, Cheyne JE, Niculescu D, Lohmann C (2015) Spontaneous activity drives local synaptic plasticity in vivo. Neuron 87:399-410.

Woo NH, Teng HK, Siao CJ, Chiaruttini C, Pang PT, Milner TA, Hempstead BL, Lu B (2005) Activation of p75NTR by proBDNF facilitates hippocampal long-term depression. Nat Neurosci 8:1069-1077.

Xu Q, Tam M, Anderson SA (2008) Fate mapping Nkx2.1-lineage cells in the mouse telencephalon. J Comp Neurol 506:16-29.

Yamashita T, Tohyama M (2003) The p75 receptor acts as a displacement factor that releases $\rho$ from $\rho$-GDI. Nat Neurosci 6:461-467.

Yamashita T, Fujitani M, Yamagishi S, Hata K, Mimura F (2005) Multiple signals regulate axon regeneration through the Nogo receptor complex. Mol Neurobiol 32:105-111.

Yang J, Siao CJ, Nagappan G, Marinic T, Jing D, McGrath K, Chen ZY, Mark W, Tessarollo L, Lee FS, Lu B, Hempstead BL (2009) Neuronal release of proBDNF. Nat Neurosci 12:113-115.

Yang J, Harte-Hargrove LC, Siao CJ, Marinic T, Clarke R, Ma Q, Jing D, Lafrancois JJ, Bath KG, Mark W, Ballon D, Lee FS, Scharfman HE, Hempstead BL (2014) proBDNF negatively regulates neuronal remodeling, synaptic transmission, and synaptic plasticity in hippocampus. Cell Rep 7:796-806.

Zanin JP, Unsain N, Anastasia A (2017) Growth factors and hormones propeptides: the unexpected adventures of the BDNF prodomain. J Neurochem 141:330-340.

Zhang L, Benedek DM, Fullerton CS, Forsten RD, Naifeh JA, Li XX, Hu XZ, Li H, Jia M, Xing GQ, Benevides KN, Ursano RJ (2014) PTSD risk is associated with BDNF Val66Met and BDNF overexpression. Mol Psychiatry 19:8-10. 